\title{
A statistical study on the development of metronidazole-alginate-chitosan nanocomposite formulations using Full factorial designs
}

Hazem Abdul Kader Sabbagh ${ }^{1}$, Samer Hasan Hussein-Al-Ali ${ }^{*}$, Mohd Zobir Hussein $^{2^{*}}$ Zead Abudayeh ${ }^{1}$.Rami Ayoub ${ }^{1}$, Suha Mujahed Abudoleh ${ }^{1}$

${ }^{1}$ Faculty of Pharmacy, Isra University, P.O. Box 22, Amman 11622, Jordan

${ }^{2}$ Materials Synthesis and Characterization Laboratory, Institute of Advanced Technology (ITMA), University Putra Malaysia, Malaysia

\section{Corresponding author:}

Samer Hasan Hussein-Al-Ali, E-mail: samer.alali@iu.edu.jo \& sameralali72@yahoo.com

Mohd Zobir Hussein, Email: mzobir@upm.edu.my

\begin{abstract}
The purpose of this study was to investigate the effect of chitosan (CS) and Alginate (Alg) polymers concentrations and $\mathrm{CaCl}_{2}$ concentration on metronidazole (MET) drug loading (LE), size particles and zeta potential. Nanocomposites were prepared by ionotropic pregelation method. A $\left(2^{1} * 3^{1} * 2^{1}\right) * 3=36$ full factorial design (FFD) was used to predict statistical equation and responses. The MET-CS-AlgNPs nanocomposites were characterized by X-ray diffraction, Fourier-transform infrared spectroscopy, thermal gravimetric analysis, scanning electron microscope and in vitro drug release studies. All data indicated the presence of drug into MET-CS-AlgNPs nanocomposites. The release profile of MET-CS-AlgNPs nanocomposites was found to be sustained
\end{abstract}

Keywords: Full Factorial Design, Optimization, metronidazole, nanocomposites, sodium alginate, Chitosan 


\section{Introduction}

In pharmacy, the term of optimization can be defined as the formulation and the process to obtain the best combination of product. In optimization steps, one generally experiments by a chain of reasonable steps, changing the variables at a time until an acceptable system is produced. Different types of optimization techniques were used in the literature; like Experimental Design (ED), Formulation by Design (FBD) and Quality by Design (QBD)[1-3].

Previously, every novel pharmaceutical formulation (PF) was designed by studying the influence of variables on the characteristics of dosage form, through changing one single variable at a time while keeping other variables constant (PF). The disadvantage of this technique does not guarantee to give the true optimum process and the product obtained may be suboptimal.

Experimental Design (ED) is a technique that is used specifically to avoid the disadvantage of PF method by examining various problems that are encountered during research, development and production (ED). It is obvious that if experiments are performed randomly, the results obtained will also be random. Therefore, it is essential to plan the experiments in method so that the relevant information will be obtained. Experimental designs (ED) is a method where the independent variables are initially screened to establish and they are more effective to the product [4-6]. The second step is the 'optimization'; in this step, a number of decisions are to be made, what plan variables will be changed to create an optimal design, and what requirements should be met. This step is the most important step in optimization design, and designers may spend much time on modeling during the optimization process[7]. The third step is called mixture designs; it contains changing mixture content and exploring how these changes will effect on the mixture. ED is a statistical method that describes a set of combinations of variables. The experimental design is chosen depending on several factors; such as number of factors, their levels, possible interactions and the order of the model.

There are various types of ED available out of which method we have to use depending on the parameters estimation. These types such as Factorial designs [8-10], Fractional factorial design [11, 12], Full factorial design (FFD) [13, 14], Plackettburman designs [15, 16], Central composite design (Box-Wilson design) [17, 18], 
Box-behnken designs (BBD) [19, 20], Taguchi design (TD) [21, 22] and Response surface designs (RSD) [23, 24].

Chitosan and alginate which are polymeric materials were widely used in development of pharmaceutical products [25]. Both are non-toxic, stable, hydrophobic for chitosan and hydrophilic for alginate polymers [26, 27]. Chitosan-alginate has been used as sustained release polymers in different dosage forms [25, 26, 28, 29]. A side effect of drugs occurs when administered in large quantities. Sustained release formulations in nanocomposites by a single dose might be a suitable way to decrease the complications and increase of the patient compliance [30-33].

The aim of this work was to investigate the effect of $\mathrm{Alg}, \mathrm{CS}$ and $\mathrm{CaCl}_{2}$ on $\mathrm{LE}$, size and zeta potential of MET.

\section{Materials and methods}

\subsection{Materials}

The chemicals which were used in this study are metronidazole $\left(\mathrm{C}_{6} \mathrm{H}_{9} \mathrm{~N}_{3} \mathrm{O}_{3}(99 \%\right.$ purity), Sigma-Aldrich) and, low viscosity sodium alginate (10-100 kDa), AZ chem., Sigma Aldrich). All HPLC solution was used from VWR (West Chester, PA). All other chemicals including acetic acid, calcium chloride were purchased from Chem CO (England).

\subsection{Preparation of CS-AlgNPs nanoparticles and MET-CS-AIgNPs nanocomposites}

The modified method is called ionotropic pregelation method was used [34]. Solutions of $\mathrm{CS}$, $\mathrm{Alg}$ and $\mathrm{CaCl}_{2}$ were first prepared. The $\mathrm{pH}$ solution of $\mathrm{CS}$ and $\mathrm{Alg}$ were adjusted to 5.5 and 5, respectively. The first step is the formation of AlgNPs pregel by adding $6 \mathrm{ml}$ of different concentrations of aqueous $\mathrm{CaCl}_{2}$ solution to $10 \mathrm{ml}$ Alg, followed by 30 minutes of stirring. The second step consisted of adding $4 \mathrm{ml}$ of CS solution to the AlgNPs pre-gel with stirring for another 30 minutes. The resultant 
composites were stirred overnight at room temperature to form uniform nanoparticles. The same procedure was used to form MET-CS-AlgNPs nanocomposites using only 100 mg MET mixed with Alg solution.

\subsection{Methodology}

First, we presented the modeling of the responses (loading efficiency, particle size and zeta potentials). Secondly, we build up the FFD to perform the experiments. Then, we used the multiple regressions to develop the loading efficiency, particle size and zeta potentials models responses. Finally, the analysis of concentration variance was used to analyze the experimental data to predict the effects and contribution of parameters on responses.

\subsubsection{Modeling of different responses}

The loading efficiency percent is the first response which was taken as a parameter and defined as the amount of total entrapped drug divided by the total nanoparticles weight. The second and third responses taken in this work was particle size and zeta potentials. Table 1 shows three independent parameters and their levels

Table 1 cutting parameters and their levels

\begin{tabular}{|c|c|c|c|c|}
\hline \multicolumn{2}{|c|}{ Parameter } & \multicolumn{3}{c|}{ levels } \\
\cline { 3 - 5 } & Low & Medium & High \\
\hline A & Alg (mg) & 200 & - & 400 \\
\hline B & CS (mg) & 50 & 100 & 200 \\
\hline C & CaCl2(mg) & 30 & - & 60 \\
\hline
\end{tabular}

\subsubsection{Full Factorial Design (FFD)}

FFD is used by researchers in their labs. It consists of several factors with separate possible levels. At FFD, the experiment takes all possible combinations of these levels across all such factors. FFD allows researchers to study the effect of each factor as 
well as their interactions on the response variable [35]. In our study, we used the FFD

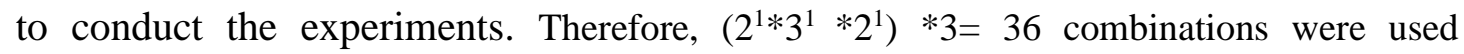
corresponding to $\mathrm{n}=3$ parameters or factors $\left(\mathrm{CS}, \mathrm{Alg}\right.$ and $\left.\mathrm{CaCl}_{2}\right)$.

Table 2 experimental parameter

\begin{tabular}{|c|c|c|c|c|c|}
\hline $\begin{array}{c}\text { Std } \\
\text { Order }\end{array}$ & $\begin{array}{c}\text { Run } \\
\text { Order }\end{array}$ & $\begin{array}{c}\text { Sample } \\
\text { code }\end{array}$ & Alg & CS & $\mathrm{CaCl}_{2}$ \\
\hline 17 & 1 & MAC1 & 200 & 200 & 30 \\
\hline 24 & 2 & MAC2 & 400 & 200 & 60 \\
\hline 10 & 3 & MAC3 & 400 & 100 & 60 \\
\hline 2 & 4 & MAC4 & 200 & 50 & 60 \\
\hline 35 & 5 & MAC5 & 400 & 200 & 30 \\
\hline 20 & 6 & MAC6 & 400 & 50 & 60 \\
\hline 32 & 7 & MAC7 & 400 & 50 & 60 \\
\hline 6 & 8 & MAC8 & 200 & 200 & 60 \\
\hline 22 & 9 & MAC9 & 400 & 100 & 60 \\
\hline 29 & 10 & MAC10 & 200 & 200 & 30 \\
\hline 36 & 11 & MAC11 & 400 & 200 & 60 \\
\hline 14 & 12 & MAC12 & 200 & 50 & 60 \\
\hline 25 & 13 & MAC13 & 200 & 50 & 30 \\
\hline 5 & 14 & MAC14 & 200 & 200 & 30 \\
\hline 9 & 15 & MAC15 & 400 & 100 & 30 \\
\hline 1 & 16 & MAC16 & 200 & 50 & 30 \\
\hline 31 & 17 & MAC17 & 400 & 50 & 30 \\
\hline 26 & 18 & MAC18 & 200 & 50 & 60 \\
\hline 3 & 19 & MAC19 & 200 & 100 & 30 \\
\hline 7 & 20 & MAC20 & 400 & 50 & 30 \\
\hline 16 & 21 & MAC21 & 200 & 100 & 60 \\
\hline 11 & 22 & MAC22 & 400 & 200 & 30 \\
\hline 28 & 23 & MAC23 & 200 & 100 & 60 \\
\hline 27 & 24 & MAC24 & 200 & 100 & 30 \\
\hline 13 & 25 & MAC25 & 200 & 50 & 30 \\
\hline 23 & 26 & MAC26 & 400 & 200 & 30 \\
\hline 30 & 27 & MAC27 & 200 & 200 & 60 \\
\hline 15 & 28 & MAC28 & 200 & 100 & 30 \\
\hline 34 & 29 & MAC29 & 400 & 100 & 60 \\
\hline 18 & 30 & MAC30 & 200 & 200 & 60 \\
\hline 12 & 31 & MAC31 & 400 & 200 & 60 \\
\hline 19 & 32 & MAC32 & 400 & 50 & 30 \\
\hline 4 & 33 & MAC33 & 200 & 100 & 60 \\
\hline 8 & 34 & MAC34 & 400 & 50 & 60 \\
\hline 33 & 35 & MAC35 & 400 & 100 & 30 \\
\hline 21 & 36 & MAC36 & 400 & 100 & 30 \\
\hline
\end{tabular}




\subsubsection{Multiple Regression method}

Multiple Regressions is a statistical method that is used to estimate the correlation between dependent and independent variables. The term of correlation coefficient $\left(\mathrm{R}^{2}\right)$ indicates how well data fit the multiple regression model. It provides a measure of how well observed outcomes are replicated by the model, as the proportion of total variation of outcomes explained by the model. An $\mathrm{R}^{2}$ close to 1 indicates that the regression model perfectly fits the data.

\subsection{The metronidazole loading efficiency}

The high speed centrifugation instrument was used in this work to determine the loading efficiency (LE) of MET in prepared nanocomposites. The method was as follows: $2.0 \mathrm{ml}$ of suspension was centrifuged (Hettich Universal $30 \mathrm{RF}$ ) at 10000 rpm for 10 min. Finally, the free drug was measured by high performance liquid chromatography (HPLC, Shimadzu, Japan). The UV detection wavelength was 323 $\mathrm{nm}$, in addition the column properties was Venusil C18 column $(4.6 \mathrm{~mm} \times 250 \mathrm{~mm}, 5$ $\mu \mathrm{m}), 25{ }^{\circ} \mathrm{C}$. The mobile phase prepared was set by mix acetonitrile/ $0.1 \%$ with phosphoric acid $(5: 95, \mathrm{v} / \mathrm{v})$ and the flow rate was $1.0 \mathrm{ml} / \mathrm{min}$. The LE were calculated as follows:

$$
\% \text { Loading Effciency }(\mathrm{LE})=\frac{\mathrm{T}_{\mathrm{p}}-\mathrm{T}_{\mathrm{f}}}{\text { mass of nanoparticles }} \times 100
$$

where $T_{p}$ is the total MET used to prepare the nanocomposites, and $T_{f}$ is the free MET in the supernatant. 


\subsection{Particle size, and zeta potential of nanocomposites}

Particle size and zeta potential of nanocomposites were analyzed through dynamic light scattering (DLS) with Zetasizer Nano $\mathrm{S}$ (Malvern, UK) at The Arab Pharmaceutical Manufacturing. The analysis was performed in triplicate at a temperature of $25^{\circ} \mathrm{C}$.

\subsection{Controlled release study of the MET from the nanocomposites}

In-vitro release of MET from nanocomposites is determined by primary method in $\mathrm{HCl}$ with $\mathrm{pH} 1.2$, using a Perkin Elmer UV-Vis spectrophotometer with $\lambda_{\max }$ of 323 nm. A suitable amount of each nanocomposite was added to $2 \mathrm{~mL}$ of the media. The cumulative amount of drug released into the solution was measured at preset time intervals at corresponding $\lambda_{\max }$.

The percentage release of the MET into the release media was obtained by:

$$
\% \text { Release }=\frac{\text { Concentration of MET at time } \mathrm{t}(\mathrm{ppm})}{\text { Concentration corresponding to } 100 \% \text { release of MET }(\mathrm{ppm})} \times 100 \quad \mathbf{2}
$$

The concentration which corresponding to $100 \%$ release was obtained by adding a known amount of nanocomposites in $2 \mathrm{~mL} \mathrm{HCl}$ in addition to using sonicate and heat the nanocomposites at $37^{\circ} \mathrm{C}$.

\subsection{Instrumentation}

Powder X-ray diffraction (XRD) patterns were used to determine the crystal structure of the samples in the range of 2-70 degrees on an XRD-6000 diffractometer (Shimadzu, Tokyo, Japan) using $\mathrm{CuK}_{\alpha}$ radiation $(\lambda=1.5406 \AA$ ) at $30 \mathrm{kV}$ and $30 \mathrm{~mA}$ at University Putra Malaysia. Fourier transform infrared spectroscopy (FTIR) spectra of 
the materials were recorded over the range of $400-4000 \mathrm{~cm}^{-1}$ on Perkin Elmer (model Smart UAIR-two). Thermogravimetric analysis was carried out using a Metter-Toledo 851e instrument (Switzerland) with a heating rate of $10^{\circ} \mathrm{C} \min ^{-1}$, in $150 \mu \mathrm{L}$ alumina crucibles and in the range of $30^{\circ} \mathrm{C}-900^{\circ} \mathrm{C}$. The zeta potential was measured at $25^{\circ} \mathrm{C}$ by dynamic light scattering (DLS) using a Malvern Zetasizer Nano ZS (Malvern Instruments, Malvern, UK). UV-Vis spectra were measured to determine the release, using a Shimadzu UV-1601 spectrophotometer at Isra University.

\section{Results and discussion}

\subsection{X-ray diffraction (XRD)for MET-CS-AlgNPs nanocomposites}

From the literature, the XRD diffract gram of CS have crystalline properties with intense peak at $2 \theta$ equals to $19.7^{\circ}$. At the same time, the XRD diffract gram of $\mathrm{Alg}$ have a semi-crystalline properties with a peak at $2 \theta$ equals to $13.6^{\circ}[36]$.

XRD patterns of pure MET, CS-AlgNPs and MET-CS-AlgNPs nanocomposites formulations are illustrated in Figure 1. The CS-AlgNPs and MET-CS-AlgNPs showed overlap between patterns of CS and Alg, which leads to the appearance of peaks at $2 \Theta=14.5^{\circ}$ and $20.6^{\circ}$, whereas peaks for AlgNPs appeared without any overlap at $2 \Theta=39.1^{\circ}$. Similar to the last data, the figure does not show any high intensity peak for MET. 


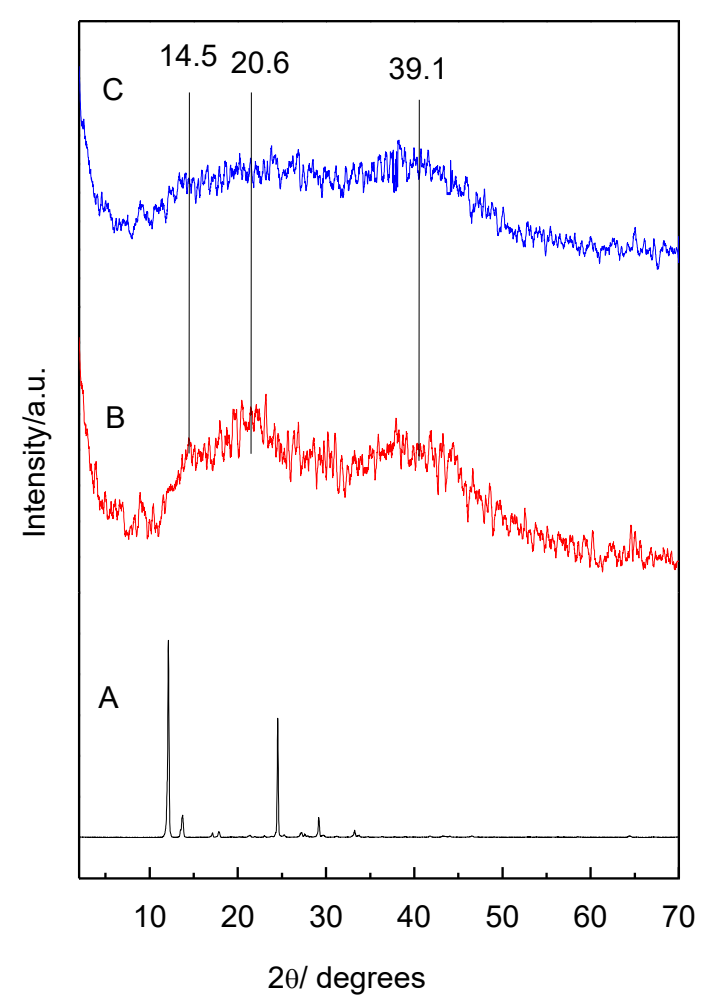

Figure 1 XRD diffraction spectra of MET (A), CS-AlgNPs (B) and MET-CS$\operatorname{AlgNPs}(\mathrm{C})$

\subsection{FTIR spectroscopic analysis of CS-AlgNPs and MET-CS-AlgNPs}

FTIR spectra of MET, CS-AlgNPs and MET-CS-AlgNPs are presented in Figure 2. For CS-AlgNPs, a band at $3296 \mathrm{~cm}^{-1}$ was observed due to O-H and N-H stretching. Absorptions due to vibration asymmetry $\mathrm{CH}_{2}$ and symmetry $\mathrm{CH}_{2}$ were located at 2930 $\mathrm{cm}^{-1}$ and $2850 \mathrm{~cm}^{-1}$, respectively. The strong band near $1589 \mathrm{~cm}^{-1}$ corresponded to vibration $\mathrm{C}=\mathrm{O}$, vibration $\mathrm{C}-\mathrm{N}$ and bending $\mathrm{N}-\mathrm{H}$ (amide I). A symmetric stretching band of the $\mathrm{COO}^{-}$group was centered near $1420 \mathrm{~cm}^{-1}[37]$. 
For MET-CS-AlgNPs, some bands were downshifting, for example $3296 \mathrm{~cm}^{-1}$ to 3283 $\mathrm{cm}^{-1}$, from $1589 \mathrm{~cm}^{-1}$ to $1585 \mathrm{~cm}^{-1}$ and from $1408 \mathrm{~cm}^{-1}$ to $1413 \mathrm{~cm}^{-1}$; this can be explained by the interaction between MET and CS-AlgNPs.

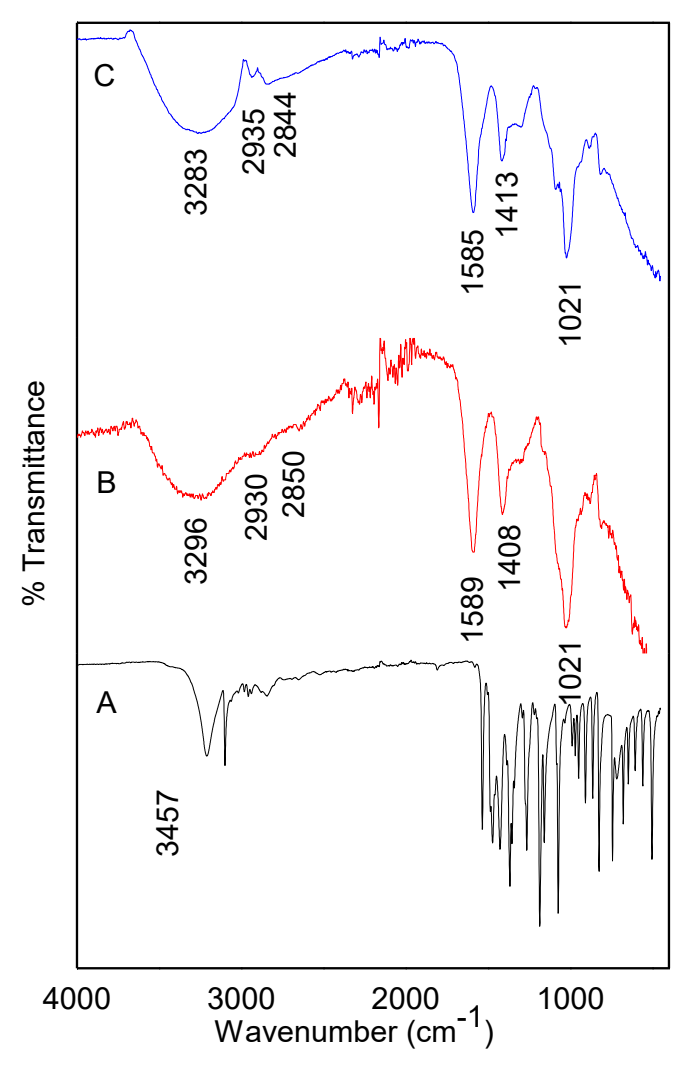

Figure 2 FTIR spectra of MET (A), CS-AlgNPs (B) and MET-CS-AlgNPs (C)

\subsection{Thermogravimetric analysis (TGA) of MET-CS-AlgNPs nanocomposites}

Thermal decomposition process of MET-CS-AlgNPs nanocomposites and pure counterparts CS-AlgNPs was evaluated by TGA. This analysis curves provided the percentage mass loss during thermal decomposition was investigated (Figure 2). The obtained results showed that a pure MET sample undergoes a one-stage thermal degradation process, while CS-AlgNPs and MET-CS-AlgNPs samples are degraded in a three-stage process. For MET sample, the decomposition process occurred 
between 137 and $288^{\circ} \mathrm{C}$ and had a mineral residue of $0.9 \%$.[38], which is due to the vaporization of volatile components [39].

The CS-AlgNPs show three main thermal stages, the first stage of the decomposition process occurred between 60 and $200^{\circ} \mathrm{C}$, which is due to vaporization of volatile components, such as water molecule immobilize between chitosan chains during the coating [40]. Focusing on the structure of $\mathrm{CS}$ and Alg, it can be seen that $\mathrm{H}_{2} \mathrm{O}$ molecules can be bounded by hydroxyl group[41]. The second responsible weight loss occurred between 200 and $520^{\circ} \mathrm{C}$ due to the release of water bounded to the functional groups of CS and Alg polymers, which was not completely removed in the first step of dehydration, also degradation of both polymers.

A third inflection point was occurred between 520 and $800{ }^{\circ} \mathrm{C}$ which may be associated with the decomposition of functional groups of both polymers which were not completely removed by previous stages.

The TGA of MET-CS-AlgNPs at Figure 2 shows also three weight loss steps similar to CS-AlgNPs. The MET-CS-AlgNPs showed $70.2 \%$ weight loss comparing to $55.3 \%$ for CS-AlgNPs. The extra weight loss at this stage is due to the incorporation of MET in the CS-AlgNPs. 


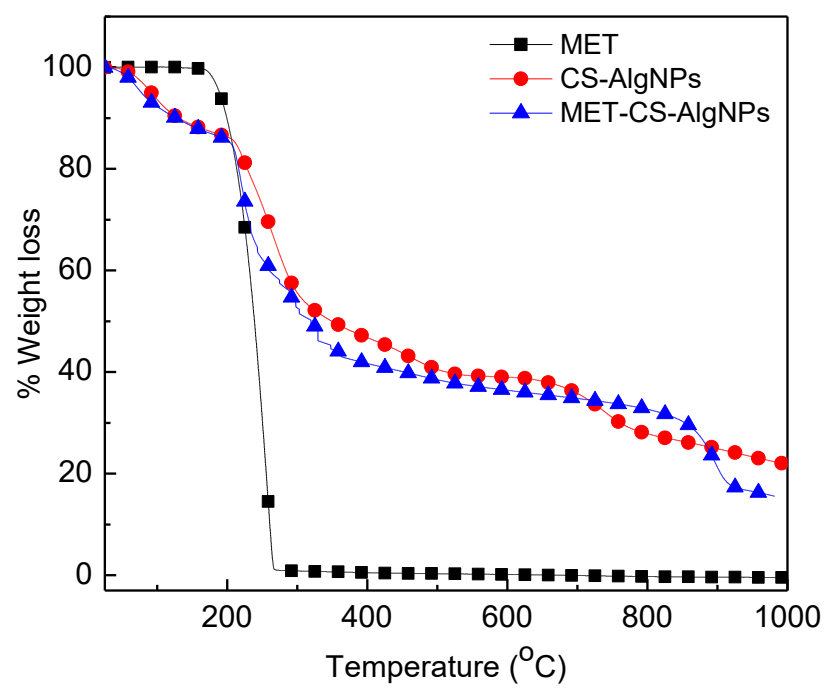

Figure 3 TGA curves are shown MET, CS-AlgNPs and MET-CS-AlgNPs nanocomposites

\subsection{Scanning Electron Microscopy (SEM)}

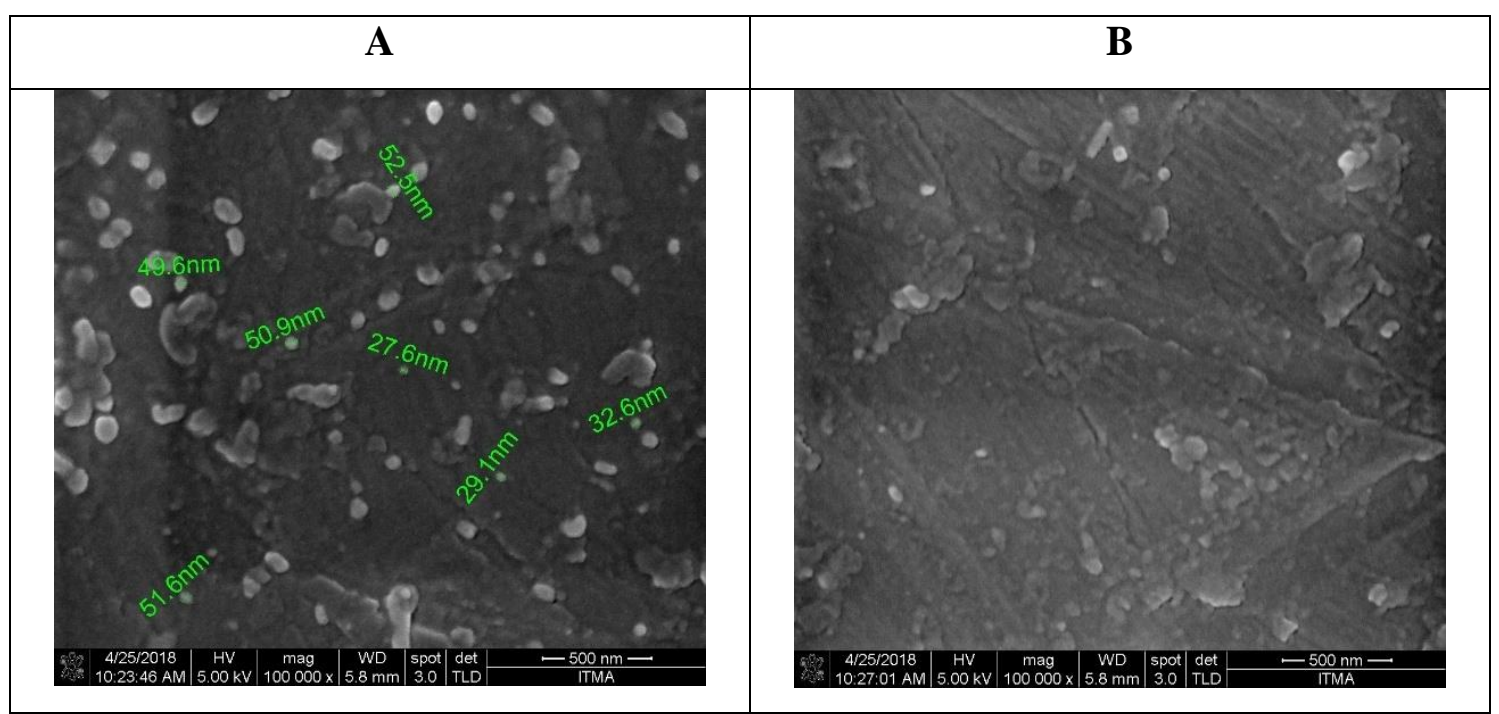

Figure 4 Scanning electron microscopy (SEM) micrographs $(100000 \times$ magnification) of CS-AIgNPs (A) and MET-CS-AlgNPs (B)

The CS-AlgNPs and metronidazole loaded CS-AlgNPs were morphologically characterized using SEM as shown in Figure 4. The micrographs of CS-AlgNPs at Figure $4 \mathrm{~A}$ show that the nanoparticle has a smooth surface and spherical shape as found in the literature [42].Figure 4B shows that metronidazole loaded CS-AlgNPs nanocomposites had also spherical shape. 


\subsection{Multiple linear regression analysis using full quadratic}

The linear (CS, $\mathrm{Alg}$, and $\mathrm{CaCl}_{2}$ ), linear-square (CS*CS, $\mathrm{Alg} * \mathrm{Alg}$, and $\mathrm{CaCl}_{2} * \mathrm{CaCl}_{2}$ ), linear-interaction equations $\left(\mathrm{CS} * \mathrm{Alg}, \mathrm{CS}^{*} \mathrm{CaCl}_{2}\right.$ and $\left.\mathrm{Alg} * \mathrm{CaCl}_{2}\right)$ have been fitted using Minitab software for LE, size and zeta potential variables. The equations can be given in terms of the coded values of the independent variables as the following (Table 3):

Table 3 Regression model for dependent variables

\begin{tabular}{|c|c|c|}
\hline Regression model & R-sq & $\begin{array}{l}\text { R-sq } \\
\text { (adi) }\end{array}$ \\
\hline $\begin{array}{l}\mathrm{LE}=-46.07+0.3252 \mathrm{Alg}-0.0045 \quad \mathrm{CS}+2.5210 \mathrm{CaCl}_{2} \\
0.000108 \mathrm{CS} * \mathrm{CS}+0.000167 \mathrm{Alg} * \mathrm{CS}- \\
0.009332 \mathrm{Alg}^{*} \mathrm{CaCl}_{2}+0.000878 \mathrm{CS}^{*} \mathrm{CaCl}_{2}\end{array}$ & $98.91 \%$ & $98.62 \%$ \\
\hline $\begin{array}{l}\text { Size }=96.7-0.4660 \mathrm{Alg}+2.856 \mathrm{CS}+2.256 \mathrm{CaCl} 2 \\
0.006495 \mathrm{CS} * \mathrm{CS}+0.001552 \mathrm{Alg} * \mathrm{CS}-0.00362 \mathrm{Alg} * \mathrm{CaCl} 2- \\
0.02457 \mathrm{CS} * \mathrm{CaCl} 2\end{array}$ & $98.68 \%$ & $98.19 \%$ \\
\hline $\begin{array}{l}\text { Potential }=-43.80+0.11391 \mathrm{Alg}-0.1673 \mathrm{CS}+0.8187 \mathrm{CaCl} 2 \\
+0.000595 \mathrm{CS} * \mathrm{CS}+0.000022 \mathrm{Alg} * \mathrm{CS}-0.002121 \mathrm{Alg} * \mathrm{CaCl} 2 \\
+0.000305 \mathrm{CS} * \mathrm{CaCl} 2\end{array}$ & $99.35 \%$ & $99.02 \%$ \\
\hline
\end{tabular}

Table 3 displayed the regression model for three dependent variables for LE, size and zeta potential. The LE model summary that R-square values were found as $98.91 \%$, $98.68 \%$ and $99.35 \%$, respectively; in addition, the Adj-R-square values were found as $98.62 \%, 98.19 \%$ and $99.02 \%$ respectively. 
Table 4 ANOVA for LE, size and zeta potential

\begin{tabular}{|c|c|c|c|c|c|c|c|c|}
\hline \multicolumn{9}{|c|}{ LE model } \\
\hline & 告 & $\begin{array}{l}\tilde{2} \\
\ddot{Z} \\
\ddot{Z}\end{array}$ & $\sum_{i=\frac{\pi}{\pi}}^{n}$ & 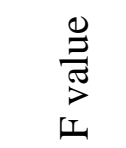 & נ̊ & $\begin{array}{l}\stackrel{0}{\Xi} \\
\stackrel{\pi}{J} \\
\qquad\end{array}$ & $\stackrel{1}{>}$ & 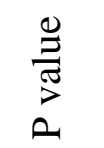 \\
\hline Model & 7 & 9585.39 & 1369.34 & 337.95 & 47.908 & 67.86 & - & 0.000 \\
\hline Alg & 1 & 1771.00 & 1771.00 & 437.07 & -7.385 & -20.91 & 1.04 & 0.000 \\
\hline $\mathrm{CS}$ & 1 & 431.85 & 431.85 & 106.58 & 4.361 & 10.32 & 1.04 & 0.000 \\
\hline $\mathrm{CaCl}_{2}$ & 1 & 208.24 & 208.24 & 51.39 & -2.532 & -7.17 & 1.04 & 0.000 \\
\hline $\mathrm{CS} * \mathrm{CS}$ & 1 & 2.09 & 2.09 & 0.51 & -0.605 & -0.72 & 1.03 & 0.480 \\
\hline Alg*CS & 1 & 236.52 & 136.52 & 9.01 & 1.252 & 3.00 & 1.04 & 0.006 \\
\hline $\begin{array}{c}\mathrm{Alg} * \mathrm{Ca} \\
\mathrm{Cl}_{2}\end{array}$ & 1 & 6545.51 & 6545.51 & 1615.40 & -13.998 & -40.19 & 1.01 & 0.000 \\
\hline $\begin{array}{c}\mathrm{CS}^{*} \mathrm{Ca} \\
\mathrm{Cl}_{2} \\
\end{array}$ & 1 & 22.71 & 22.71 & 5.60 & 0.987 & 2.37 & 1.04 & 0.026 \\
\hline $\begin{array}{l}\text { Lack- } \\
\text { of-fit }\end{array}$ & 4 & 20.77 & 5.19 & 1.35 & - & - & - & 0.283 \\
\hline \multicolumn{9}{|c|}{ Size model } \\
\hline Model & 7 & 141548 & 20221.1 & 202.86 & 185.00 & 51.90 & - & 0.000 \\
\hline Alg & 1 & 45889 & 45889.3 & 460.35 & -43.50 & -21.46 & 1.10 & 0.000 \\
\hline CS & 1 & 30270 & 30270 & 303.67 & 44.42 & 17.43 & 1.12 & 0.000 \\
\hline $\mathrm{CaCl}_{2}$ & 1 & 19575 & 19574.9 & 196.37 & -28.53 & -14.01 & 1.12 & 0.000 \\
\hline $\mathrm{CS} * \mathrm{CS}$ & 1 & 6104 & 6103.7 & 61.23 & -36.54 & -7.83 & 1.13 & 0.000 \\
\hline $\mathrm{Alg} * \mathrm{CS}$ & 1 & 1963 & 1962.6 & 19.69 & 11.64 & 4.44 & 1.19 & 0.000 \\
\hline $\begin{array}{c}\mathrm{Alg}^{*} \mathrm{Ca} \\
\mathrm{Cl}_{2}\end{array}$ & 1 & 700 & 700.2 & 7.02 & -5.43 & -2.65 & 1.06 & 0.016 \\
\hline $\begin{array}{c}\mathrm{CS}^{*} \mathrm{Ca} \\
\mathrm{Cl}_{2} \\
\end{array}$ & 1 & 11146 & 11145.6 & 111.81 & -27.64 & -10.57 & 1.17 & 0.000 \\
\hline $\begin{array}{c}\text { Lack- } \\
\text { of-fit }\end{array}$ & 4 & 173 & 43.4 & 0.38 & - & - & - & 0.821 \\
\hline \multicolumn{9}{|c|}{ Potential model } \\
\hline Model & 7 & 399.875 & 57.125 & 303.51 & -10.501 & -44.19 & - & 0.000 \\
\hline Alg & 1 & 85.093 & 85.093 & 452.11 & 2.1189 & 21.26 & 1.07 & 0.000 \\
\hline $\mathrm{CS}$ & 1 & 0.256 & 0.256 & 1.36 & 0.133 & 1.17 & 1.19 & 0.263 \\
\hline $\mathrm{CaCl}_{2}$ & 1 & 191.991 & 191.991 & 1020.07 & 3.308 & 31.94 & 1.25 & 0.000 \\
\hline $\mathrm{CS} * \mathrm{CS}$ & 1 & 30.172 & 30.172 & 160.31 & 3.347 & 12.66 & 1.13 & 0.000 \\
\hline Alg*CS & 1 & 0.404 & 0.404 & 2.15 & 0.164 & 1.47 & 1.17 & 0.165 \\
\hline
\end{tabular}




\begin{tabular}{|c|c|c|c|c|c|c|c|c|}
\hline $\begin{array}{c}\mathrm{Alg} * \mathrm{Ca} \\
\mathrm{Cl}_{2}\end{array}$ & 1 & 181.922 & 181.922 & 966.57 & -3.182 & -31.09 & 1.22 & 0.000 \\
\hline $\begin{array}{c}\mathrm{CS} \mathrm{Ca} \\
\mathrm{Cl}_{2}\end{array}$ & 1 & 1.855 & 1.855 & 9.85 & 0.344 & 3.14 & 1.05 & 0.007 \\
\hline $\begin{array}{c}\text { Lack- } \\
\text { of-fit }\end{array}$ & 3 & 0.562 & 0.187 & 0.99 & - & - & - & 0.432 \\
\hline
\end{tabular}

DF: degrees of freedom, SS: Sum of squares, F: F-test value and P: error variance

Table 4 displayed the ANOVA table for the second-order model proposed for LE, zeta size and zeta potential given in suggested models. It is clear that the P-value is less than 0.05 showing the model which is significant at $95 \%$ confidence level. These LE, zeta size and zeta potential models show that lack-of-fit error value is insignificant $(0.283,0.821$ and 0.432 respectively) indicating that the fitted model is accurate enough to predict the response. The mathematical models were developed to determine the optimal values of the CS-Alg-MET formulations conditions leading to maximum value of LE, minimum value of zeta size and negative value $(\sim 20 \mathrm{mV})$ of zeta potential.

\subsection{Evaluation of the models}

\subsubsection{Pareto chart of responses standardized effect and Normal Plot of the Standardized effects}

A Pareto charts at Figure 5 is a graphical overview of the process factors and/or interactions of influence, in ranking order from the most influencing to the least influencing. A threshold line ( $\mathrm{P}$ value 0.05$)$ indicates the minimum magnitude of statistically significant effects, considering the statistical significance of $95 \%$.

The Figure 5A indicates that the effect of BB i.e. CS x CS is statistically insignificant toward LE. The effect of $\mathrm{AC}\left(\mathrm{Alg} \times \mathrm{CaCl}_{2}\right)$ has the highest standardized effect on the LE followed by A, B, C, AB and BC. Hence, the term BB should not be considered for the empirical relation. The insignificance of factor BB can also be reasserted from the normal plot (Figure 6A), in which, the points that do not fall near the fitted line 
are important. The factors having negligible effect on the output response tend to be smaller and are centered around zero.

The Figure 5B represents the effect of different parameters toward zeta size. The results indicate that all the effect is statistically significant. The effect of A (Alg) has the highest standardized effect on the zeta size followed by $\mathrm{B}, \mathrm{C}, \mathrm{BC}, \mathrm{BB}, \mathrm{AB}$ and AC. Hence, the term BB should not be considered for the empirical relation. All the significance of factors can be shown at the normal plot (Figure 6B).

Figure 5C shows the different factors effect on the zeta potential response. It can be clearly seen that main factors $(\mathrm{A}$, and $\mathrm{C})$, Square factors $\left(\mathrm{B}^{*} \mathrm{~B}\right)$ and 2- way interaction $(\mathrm{A} * \mathrm{C}$ and $\mathrm{B} * \mathrm{C})$ have a statistically significant effect on the response. The effect of $\mathrm{C}$ $\left(\mathrm{CaCl}_{2}\right)$ has the highest standardized effect on the zeta potential followed by $\mathrm{AC}, \mathrm{A}$, $\mathrm{BB}$, and $\mathrm{BC}$. Hence, the terms $\mathrm{AB}$ and $\mathrm{B}$ should not be considered for the empirical relation. The insignificance of the factors $\mathrm{AB}$ and $\mathrm{B}$ can also be reasserted from the normal plot (Figure 6C), in which, the points that do not fall near the fitted line are important. 


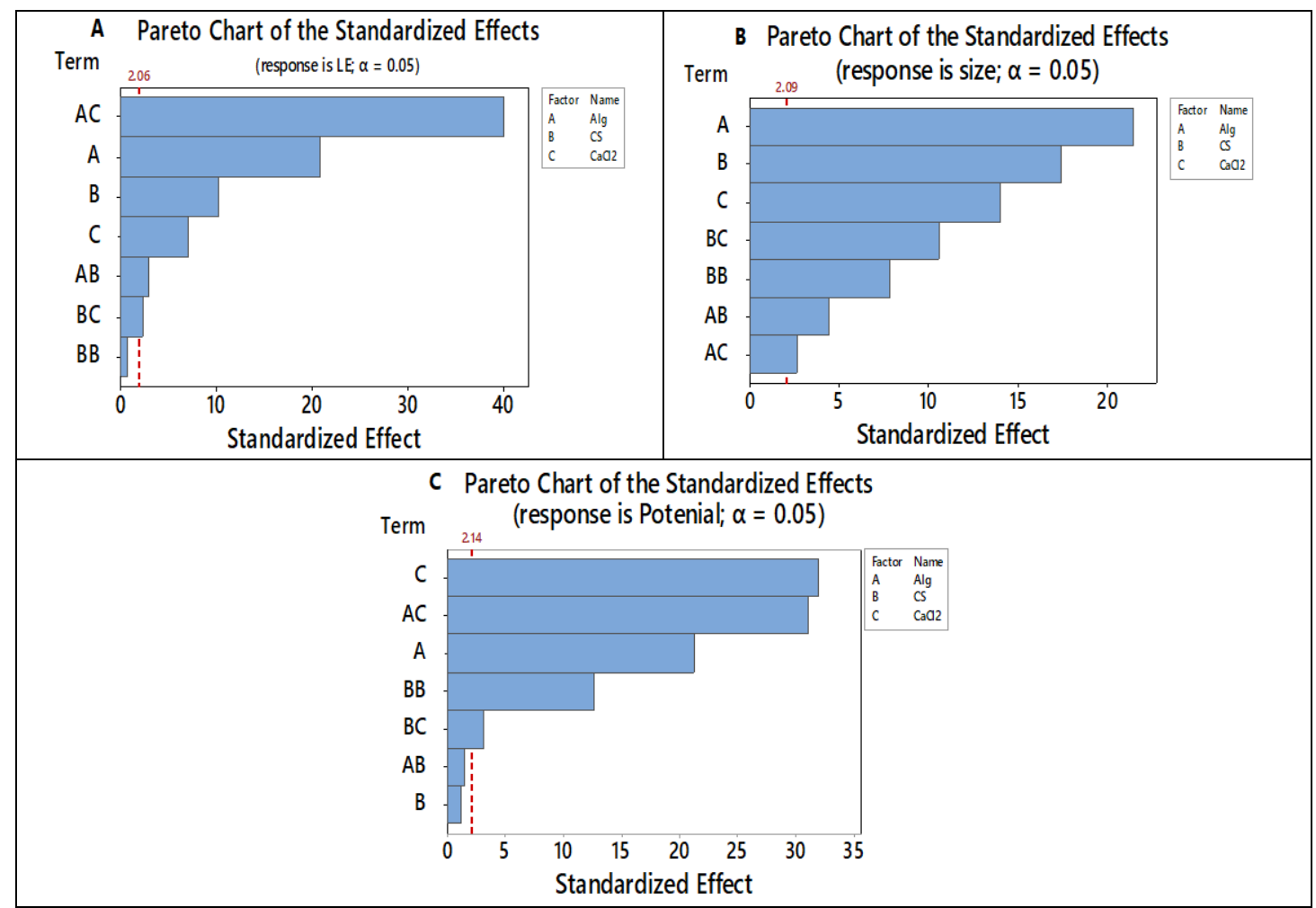

Figure 5 Pareto Chart of the Standardized effects toward LE (A), zeta size (B) and zeta potential $(\mathrm{C})$

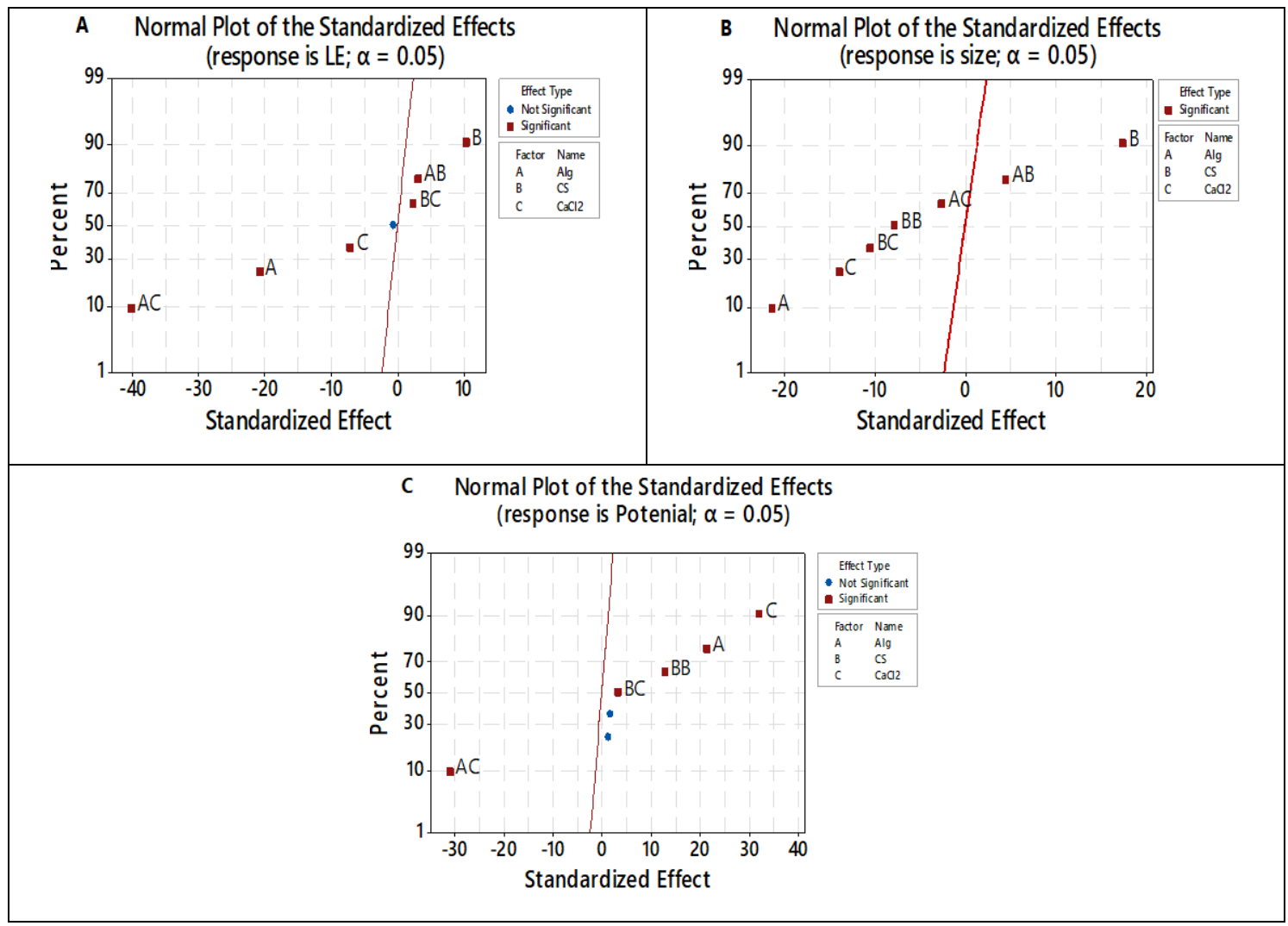

Figure 6 Normal Plot of the Standardized effects toward LE (A), zeta size (B) and zeta potential $(C)$ 


\subsubsection{Normal probability plot}

Normal probability is used commonly in the drug formulation. For example, Ghadiri, M [43], and Javaid [44] recommend use of these plots for estimating the goodness of fit of a hypothesized distribution. If the sample is actually distributed as hypothesized, one would expect the plot of the ordered observations at $\mathrm{Y}$ axis versus the order statistic means at $\mathrm{X}$ axis to be approximately linear. Thus the correlation coefficient which measures the degree of linear association between two random variables is an appropriate test statistics. A correlation coefficient of 1.0 shows a perfect correlation between two variables.

In our work, the residual analysis was employed to study the random behavior of the residuals, and normal probability was prepared for residual errors of LE, zeta size and zeta potential responses, as shown in Figure7 (A-C). The plot of this figure is normally distributed and resembles a straight line. There is no evidence of nonnormality and any pointing to possible outliers

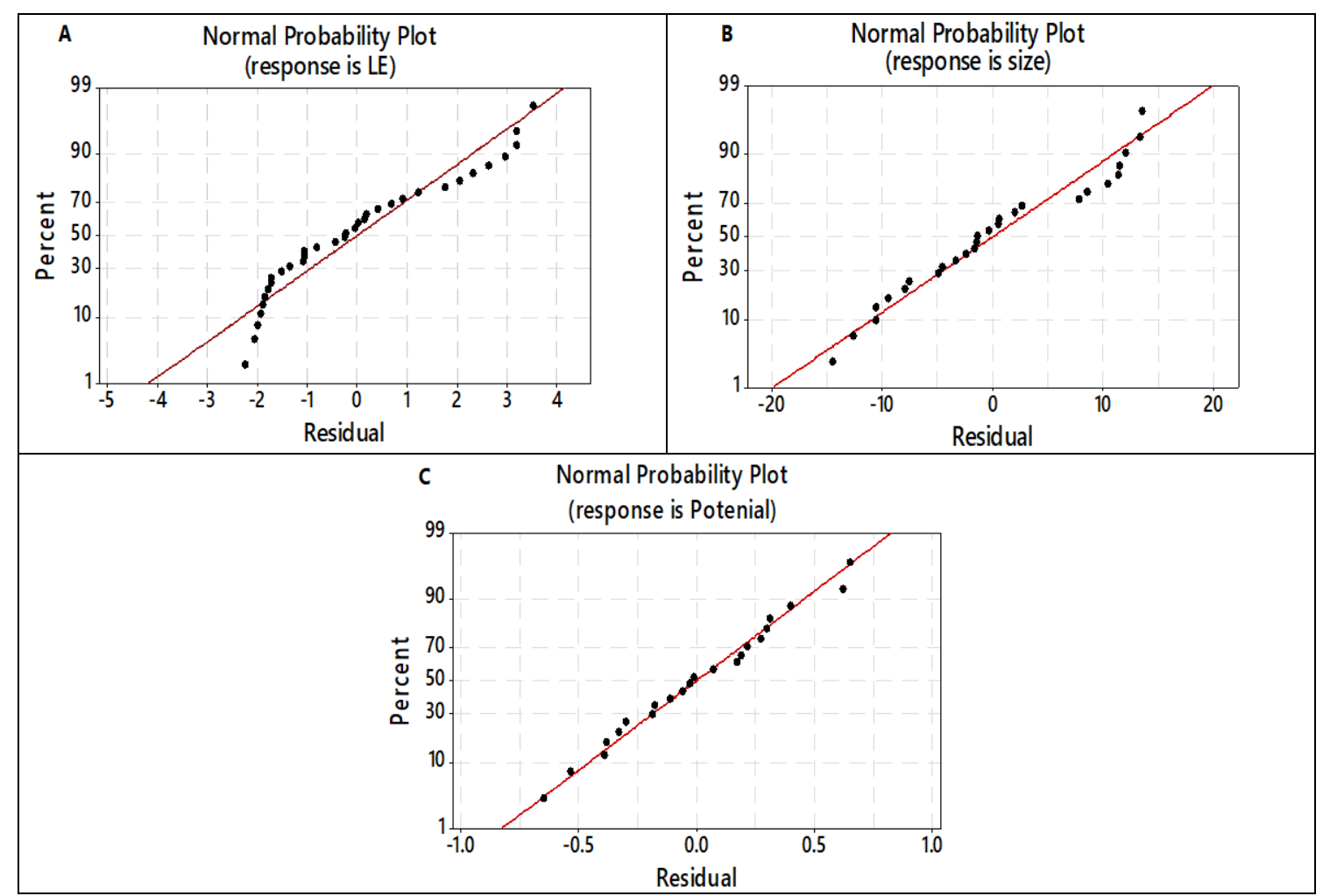

Figure 7 Normal probability plots for LE (A), zeta size (B), and zeta potential (C). 


\subsubsection{Residuals versus fitted value}

The residual analysis plot consists of residuals and fitted value on the $y$ and $\mathrm{x}$ axis, respectively. The plot is used to detect three things, its non-linearity, unequal error variances, and outliers.

At Figure 8 A-C, the residuals "bounce randomly" around the zero line; this indicates that the relationship is linear and reasonable. In addition, the residuals roughly form a "horizontal band" around the zero line, which indicates that the variances of the error terms are equal. Finally, there is no one residual "stands out" from the basic random pattern of residuals and this means that there are no outliers.

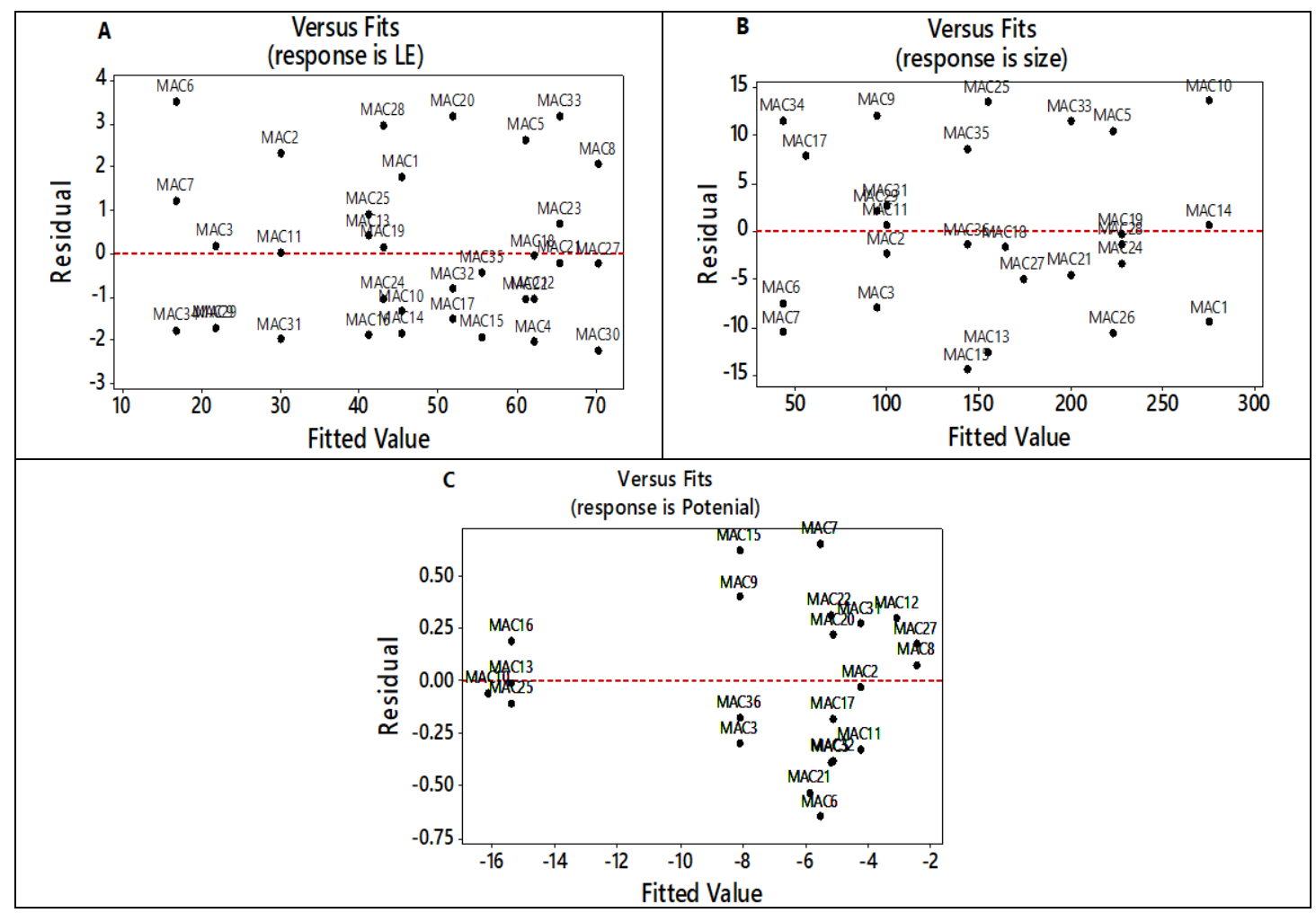

Figure 8 Residuals versus fitted value for LE (A), zeta size (B), and zeta potential (C). 


\subsubsection{Residuals versus observation order}

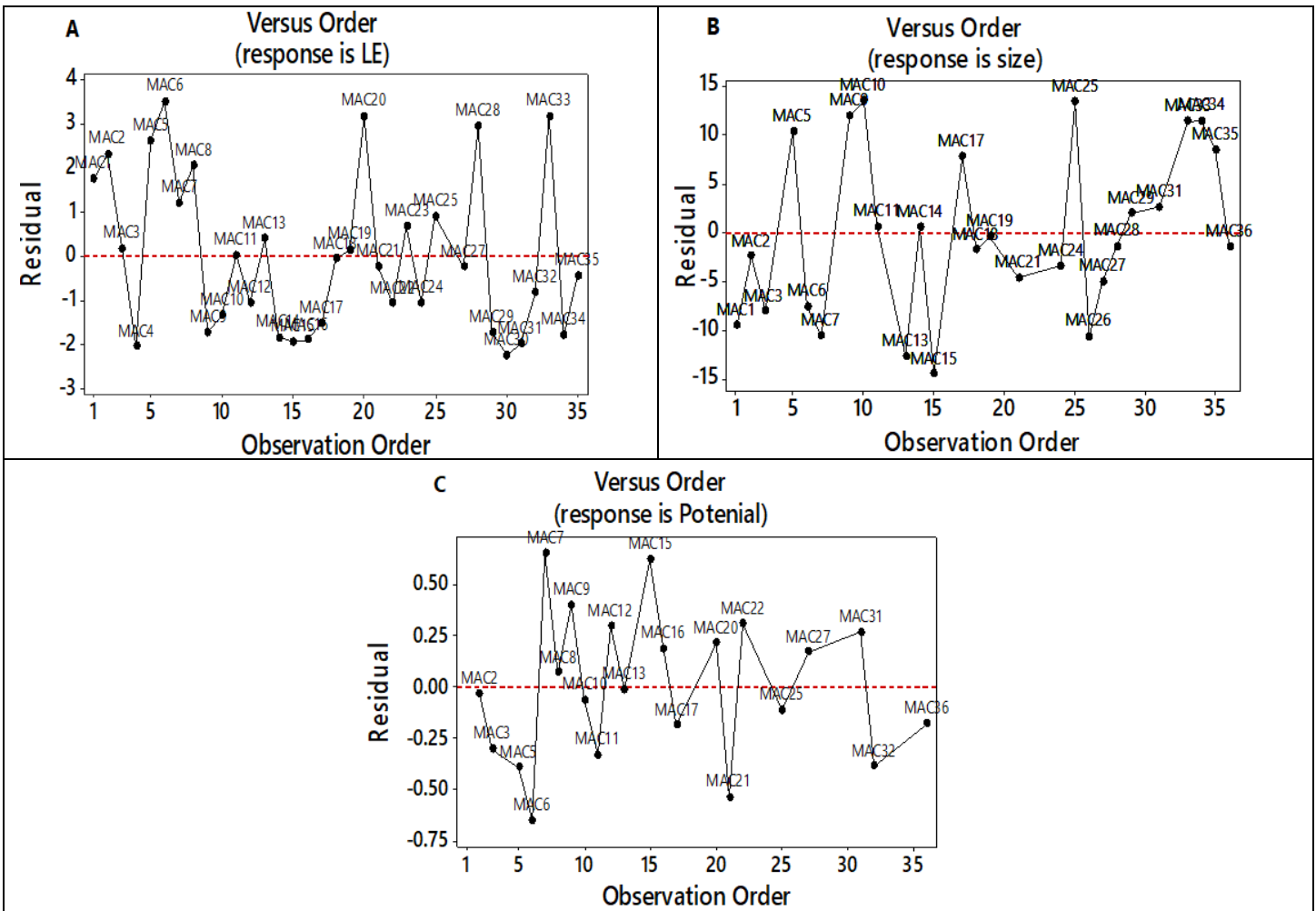

Figure 9 Residuals versus observation order for LE (A), zeta size (B) and zeta potential $(\mathbf{C})$.

The use of the residuals versus observation order is to verify the assumption that the residuals are independent from one another. Independent residuals show no trends or patterns when displayed in time order. The residuals at Figure 9 (A-C) fall randomly around the center line, this is indicating that residuals are near each other, correlated, and thus, not independent. 
3.6.5 Contour plot and Surface plot of LE and zeta size against selected independent variables

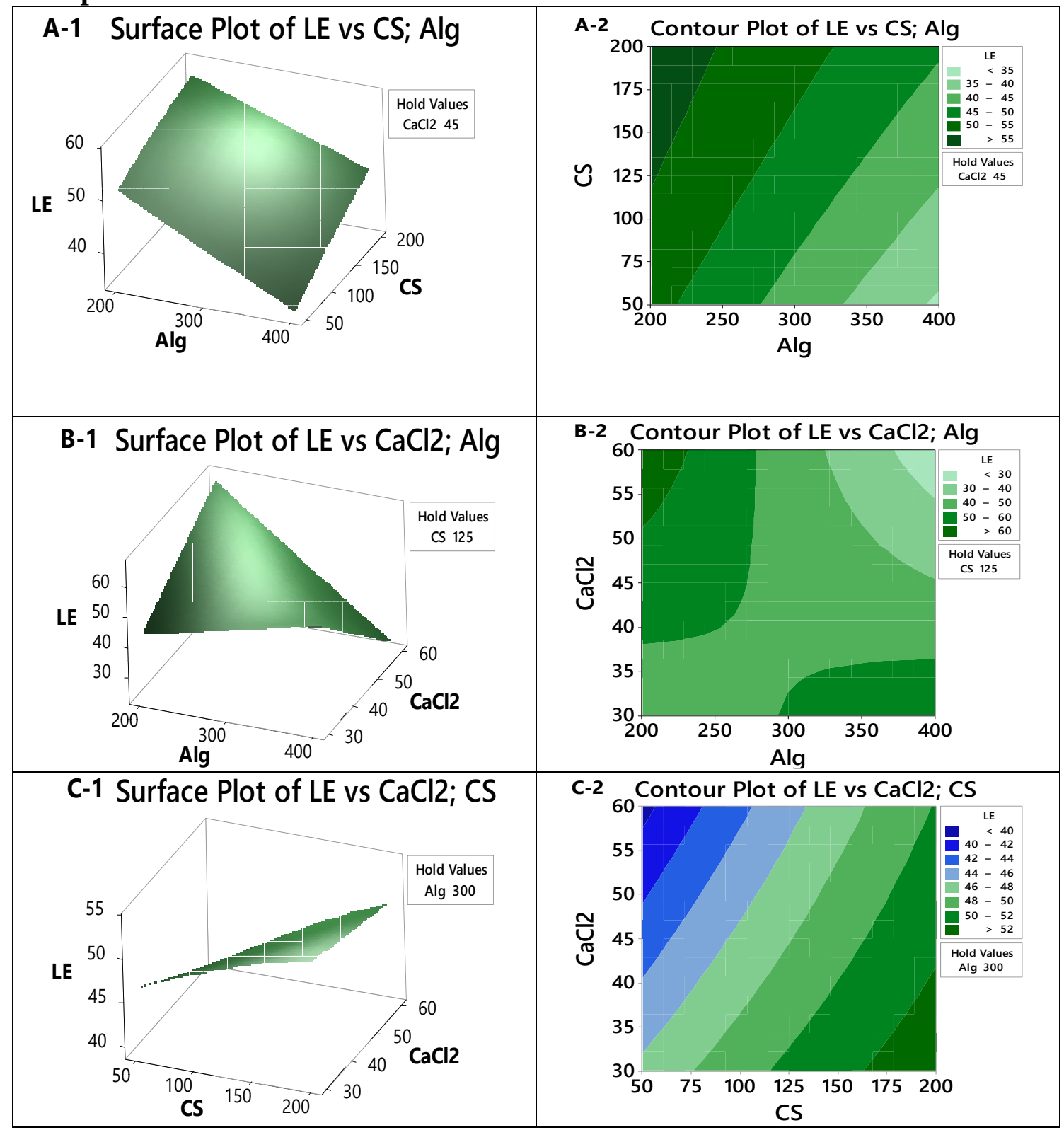

Figure 10 the contour plot and response surface of the LE with variances of $\mathrm{CaCl}_{2}, \mathrm{CS}$ and Alg concentrations.

The effect of the formulation and process variables on LE response can be evaluated by studying the contour and response surface plots. From Figure 10 A-1, the response plots of LE as a function of CS and Alg concentrations. Increasing the concentration of CS and decreasing the Alg can afford more space to LE (Figure 10A), at the same time, increasing the concentration of $\mathrm{CS}$ and $\mathrm{CaCl}_{2}$ leads to the increase of LE (Figure $10 \mathrm{C}$ ). The Figure $10 \mathrm{C}$ shows dual zone for the highest LE. Increasing the Alg 
concentration and decreasing the $\mathrm{CaCl}_{2}$ concentration, in addition to decreasing the Alg concentration and increasing the $\mathrm{CaCl}_{2}$ concentration, lead to high percentage of LE.

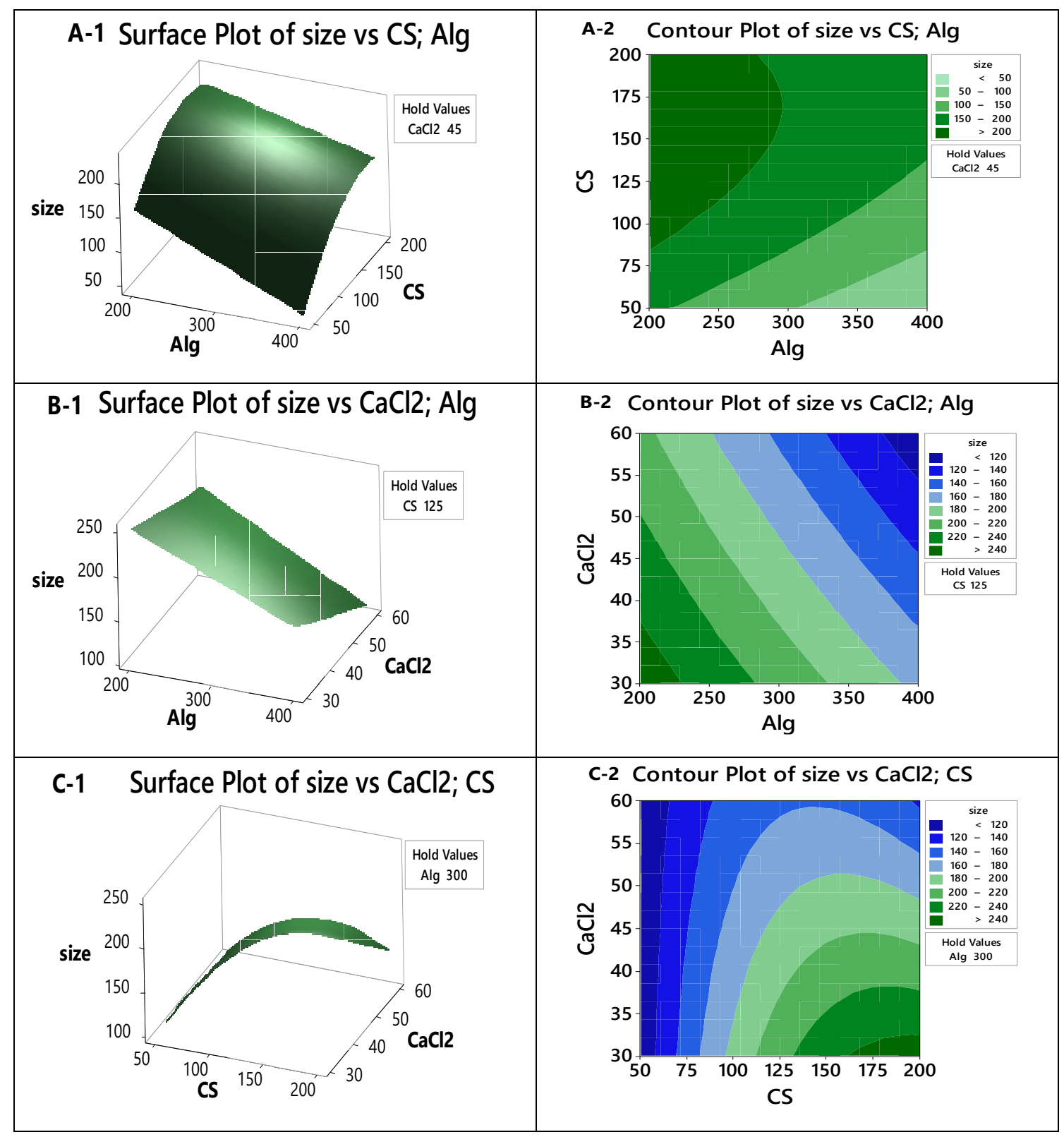

Figure 11 the contour plot and response surface of the zeta size with variances of $\mathrm{CaCl}_{2}, \mathrm{CS}$ and Alg concentrations.

As can be seen in Figure 11 A-1, the minimum zeta size has been collected by using high concentration of Alg and the lowest concentration of CS. From Figure 11 A-2, the particle size below $50 \mathrm{~nm}$ can be prepared by using $50 \mathrm{mg}$ of CS and $400 \mathrm{mg}$ of Alg. As can be seen in Figure 11B-1, the particle size below $120 \mathrm{~nm}$ can be 
prepared by using $400 \mathrm{mg}$ of $\mathrm{Alg}$ and $60 \mathrm{mg}$ of $\mathrm{CaCl}_{2}$ (Figure 11B-2). In the case of $\mathrm{CS}$ and $\mathrm{CaCl}_{2}$ variables at Figure 11C, the lower size than $120 \mathrm{~nm}$ can be collected by using CS concentration of $200 \mathrm{ng}$ and $\mathrm{CaCl}_{2}$ range between 30 and $60 \mathrm{mg}$.

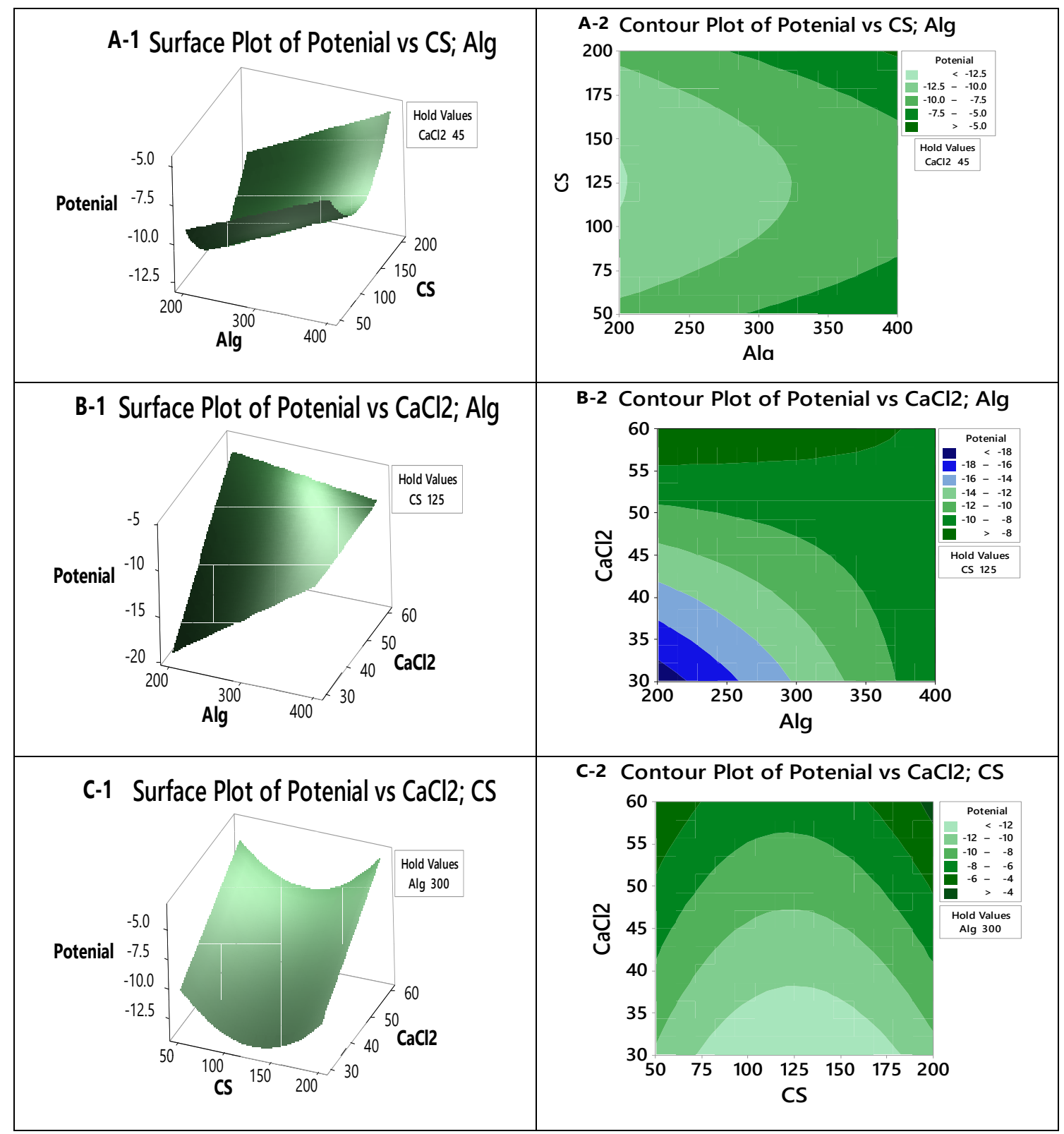

Figure 12 the contour plot and response surface of the zeta potential with variances of $\mathrm{CaCl}_{2}, \mathrm{CS}$ and $\mathrm{Alg}$ concentrations.

Figure 12 shows the 3D response surface and contour plot of the combined effect of $\mathrm{CS}, \mathrm{Alg}$ and $\mathrm{CaCl}_{2}$ on the zeta potential charge. It can be revealed from the plot that all the variables have effect on zeta potential. Figure 12 A shows the combined effect of Alg and CS concentrations. As can be seen, the zeta potential is bigger than$5.0 \mathrm{mV}$ and it was obtained at concentration of Alg which is bigger than $300 \mathrm{mg}$ and 
CS concentration between 50-75 mg and 160-200 mg; whereas zeta potential is lower than $-12.5 \mathrm{mV}$ which was obtained at concentration of Alg below than $300 \mathrm{mg}$ and CS concentration between 60-185 mg. Figure 12B shows the contour plot of the effect of $\mathrm{Alg}$ and $\mathrm{CaCl}_{2}$ on the zeta potential. The zeta potential in the Figure obtained between -8 and $-18 \mathrm{mV}$; the zeta potential around $18 \mathrm{mV}$ can be obtained by low concentration of both $\mathrm{Alg}$ and $\mathrm{CaCl}_{2}$, whereas zeta potential around $-8 \mathrm{mV}$ can be obtained at $\mathrm{Alg}$ concentration between 200-350 mg of Alg and with concentration of $\mathrm{CaCl}_{2}$ between $55-60 \mathrm{mg}$.

Figure $12 \mathrm{C}$ shows the $3 \mathrm{D}$ surface and contour plots represent a rising ridge surface. As the color gets darker, the zeta potential response become at $-4 \mathrm{mV}$, this is occur at high concentration of $\mathrm{CaCl}_{2}(55-60 \mathrm{mg})$ and $\mathrm{CS}$ concentrations below $50 \mathrm{mg}$ and higher than $200 \mathrm{mg}$. The zeta potential response at $-4 \mathrm{mV}$ can be collected at low concentration of $\mathrm{CaCl}_{2}$ (below $30 \mathrm{mV}$ ) and CS concentration between 75-175 mg.

\subsubsection{Main Effects Plot for $\mathrm{LE}$, zeta size and zeta potential}

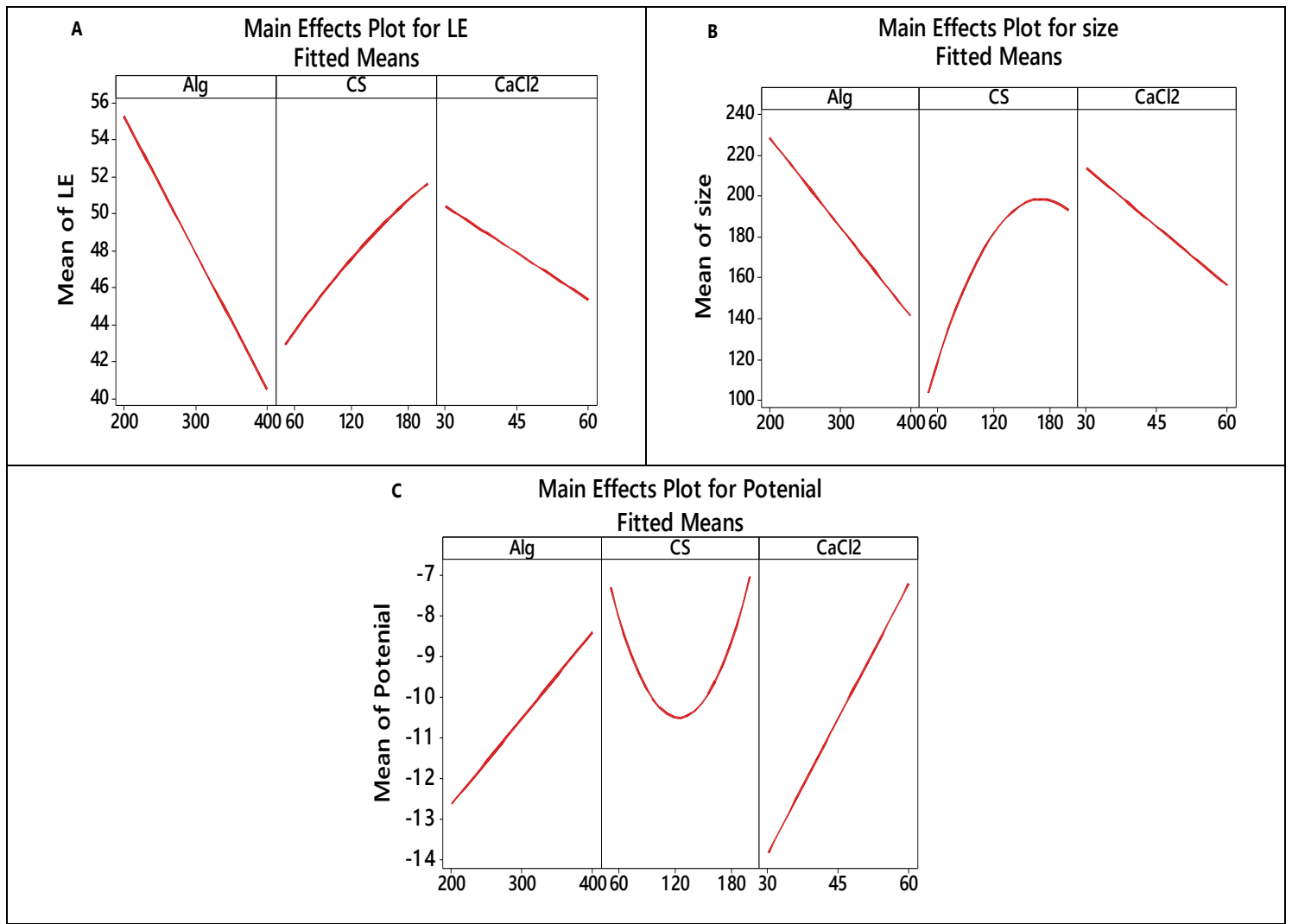

Figure 13 Main Effects Plot for LE, zeta size and zeta potential

The main effects plot at Figure 13 use a main effects plot (CS, $\mathrm{Alg}$ and $\mathrm{CaCl}_{2}$ ) to examine differences between level means for LE, zeta size and zeta potential factors. 
All factors seem to affect the LE, zeta size and zeta potential because the line is not horizontal. At Figure 13A, Alg with concentration of $200 \mathrm{mg}$ show higher LE comparing with $400 \mathrm{mg} \mathrm{Alg}$. A $\mathrm{CaCl}_{2}$ with $30 \mathrm{mg}$ has a higher LE mean than $60 \mathrm{mg}$. The CS also affects the LE. CS with $200 \mathrm{mg}$ had a higher LE mean than 100 and 50 mg.

It is evident from Figure 13B that zeta size is minimum at the highest level of Alg and $\mathrm{CaCl}_{2}$ and the lowest level of CS.

From Figure 13C, the lines connecting level of $\mathrm{CS}, \mathrm{Alg}$ and $\mathrm{CaCl}_{2}$ factors are not horizontal indicating that each factor affects differently. The $-11,-10$ and $-14 \mathrm{mV}$ value of the mean of zeta potential are observed at $200 \mathrm{mg}$ of Alg, $120 \mathrm{mg}$ of CS and $30 \mathrm{mg}$ of $\mathrm{CaCl}_{2}$.

\subsubsection{The interaction between the factor effects toward LE, zeta size and zeta potential}

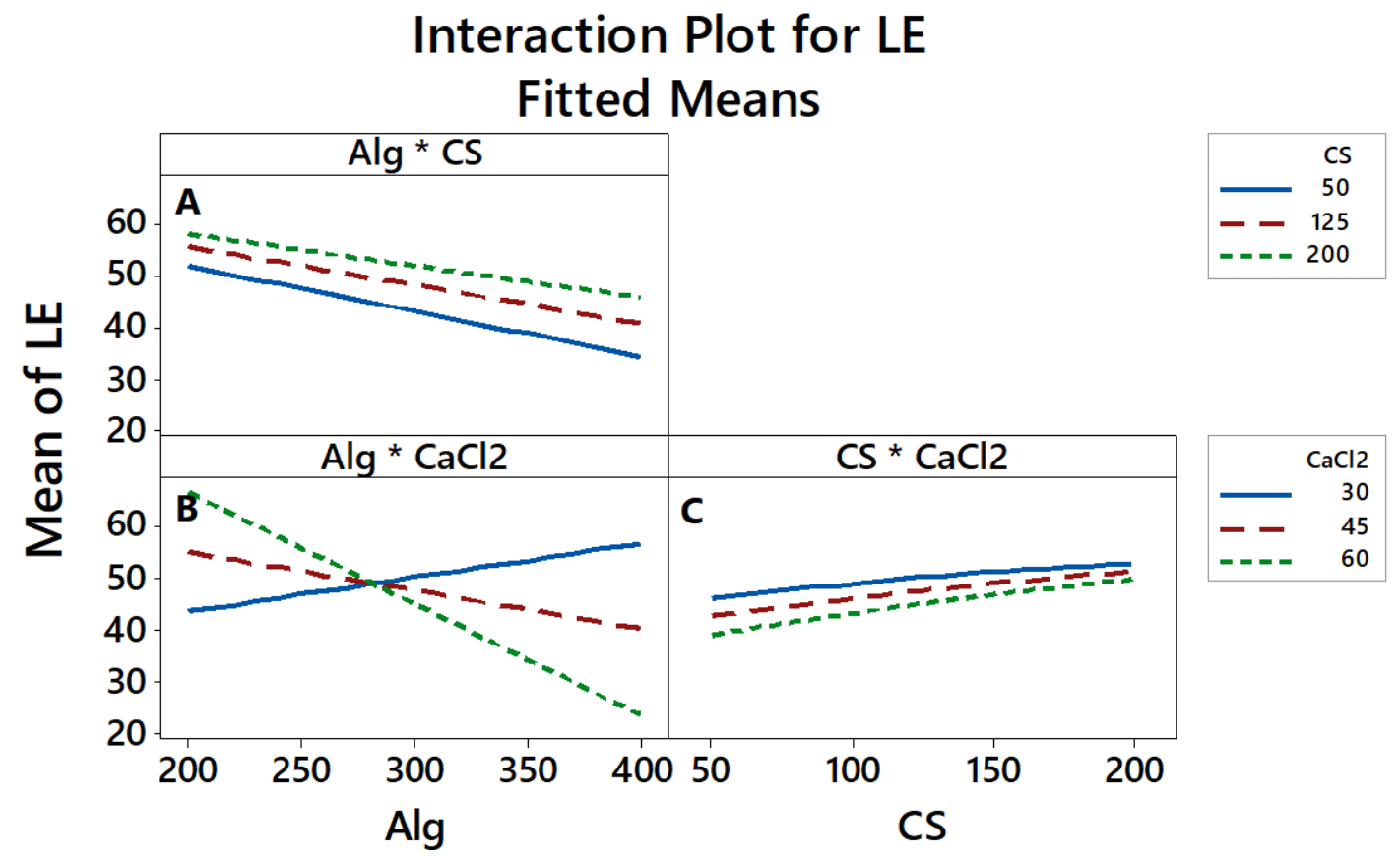

\section{Figure 14 Interaction effects of factors on the loading efficiency}

The interaction plot at Figure 14, 15 and 16 show how the relationship between one independent factor and a continuous response depends on the value of the second independent factor. This plot displays means for the levels of one factor on the $\mathrm{x}$-axis and a separate line for each level of the other factor. The Parallel lines in interaction effect figure indicate that there is no relationship between the variables. An 
interaction occurs, the more nonparallel the lines are, the greater the strength of the interaction becomes.

In this interaction plot, the lines at Figure $14 \mathrm{~A}$ and $\mathrm{C}$ are parallel; this indicates that there is no relationship between the variables. The interaction at Figure 14B has nonparallel line; this interaction effect indicates that the relationship between Alg and $\mathrm{LE}$ depends on the value of $\mathrm{CaCl}_{2}$. For example, if you use $\mathrm{Alg}$ with $300 \mathrm{mg}, \mathrm{CaCl}_{2}$ with 30,45 and $60 \mathrm{mg}$ is associated with the $50 \%$ LE mean.

\section{Interaction Plot for size Fitted Means}

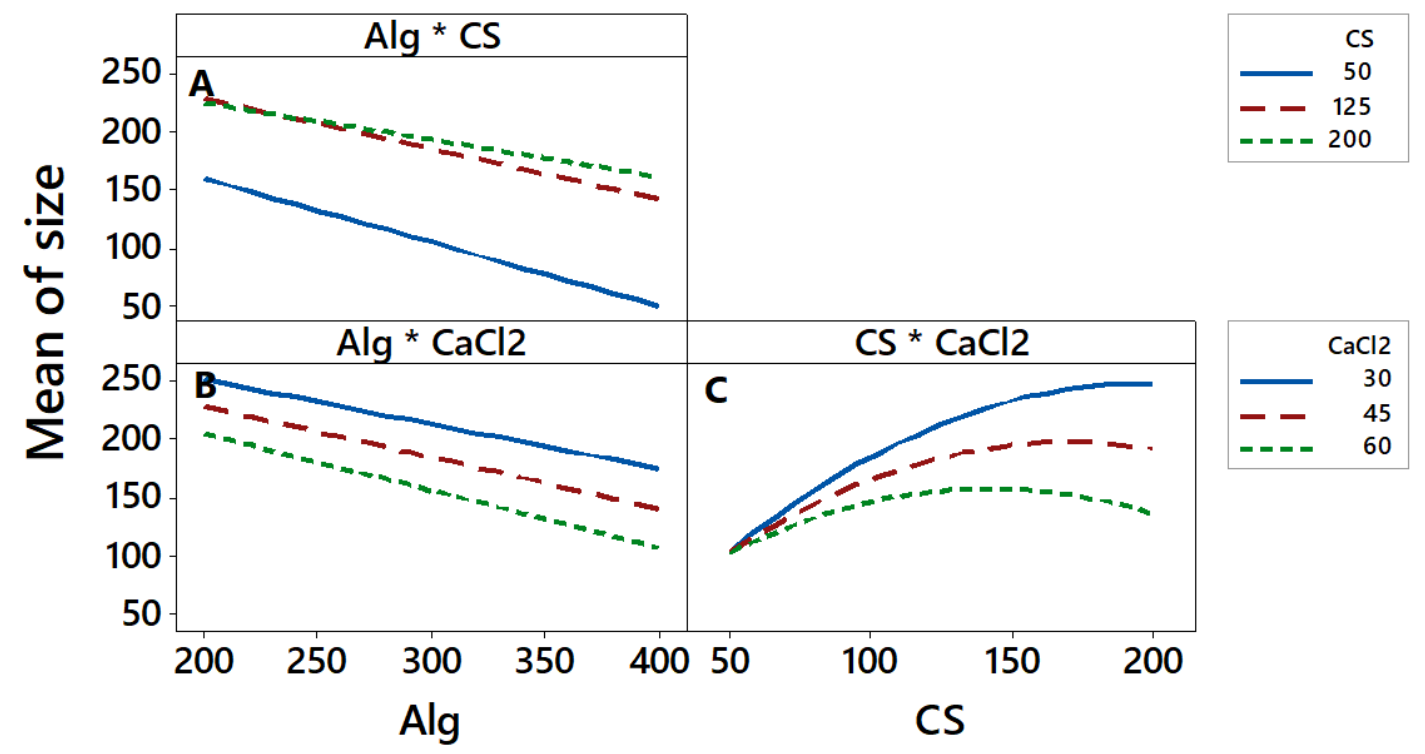

Figure 15 Interaction effects of factors on the zeta size

As Figure 15 shows, there is an interaction between the Alg*CS (Figure 15A) and $\mathrm{CS}^{*} \mathrm{CaCl}_{2}$ (Figure 15C). The Figure 15A shows that there is a significant interaction between factors Alg and CS. The green and red lines (200 and $125 \mathrm{mg}$ CS respectively) show that the mean size response decreases when the factor Alg level is low. While in Figure 15C, the green, red and blue lines which are corresponding to 60,45 and $30 \mathrm{mg} \mathrm{CaCl}_{2}$ respectively shows that the size mean response decreases when the factor CS level is low. 


\section{Interaction Plot for Potenial Fitted Means}

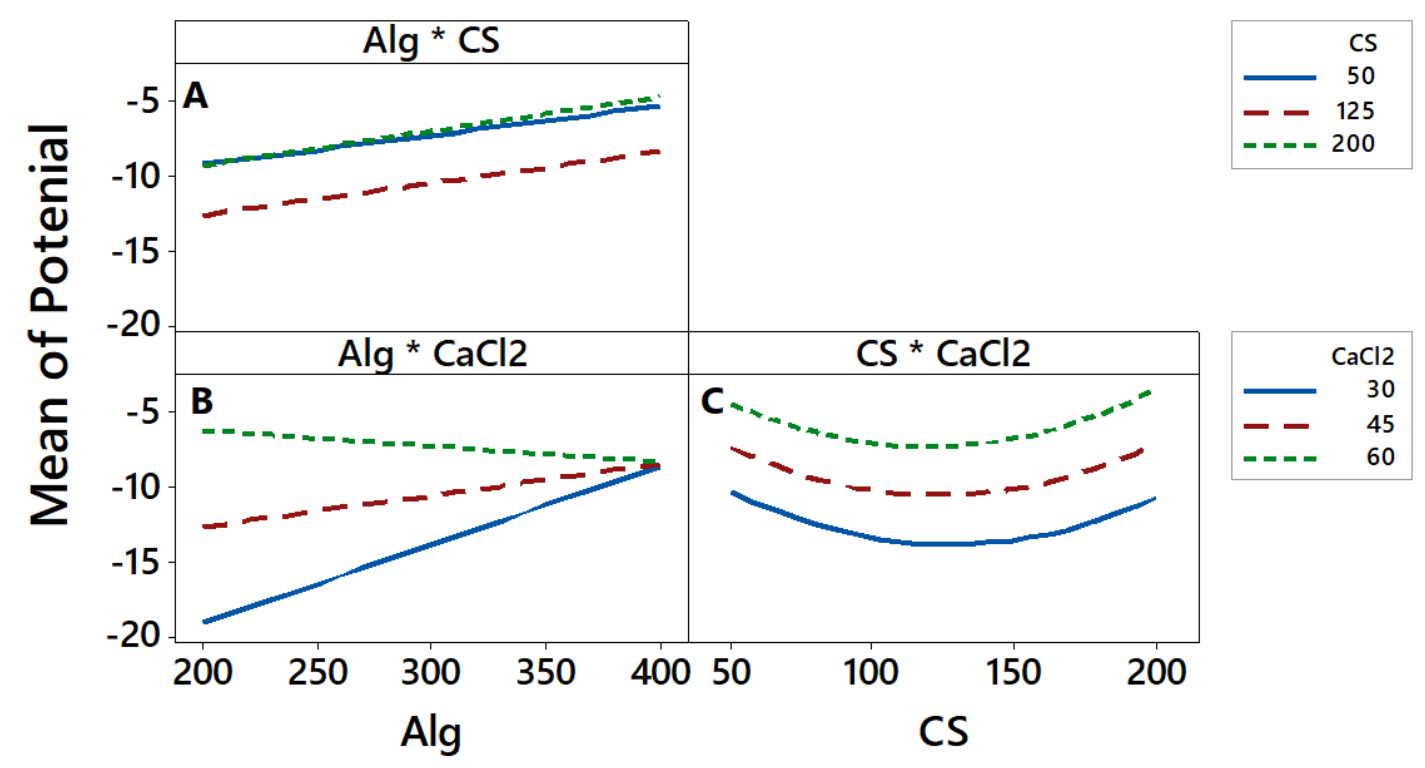

Figure 16 Interaction effects of factors on the zeta potential

At interaction plot for Figure 16A and B, the lines are not parallel; this interaction effect indicates that the relationship between Alg concentration and zeta potential depends on the value of $\mathrm{CS}$ (Figure 16A) and $\mathrm{CaCl}_{2}$ (Figure 16B). For example, if we use $\mathrm{Alg}$ with concentration $200 \mathrm{mg}$, then $\mathrm{CaCl}_{2}$ at $30 \mathrm{mg}$ is associated with the -20 $\mathrm{mV}$ (Figure 16B). However, if we use Alg with concentration $200 \mathrm{mg}$, then CS with 50 and $125 \mathrm{mg}$ is associated with the $-10 \mathrm{mV}$ (Figure 16A).

\subsection{Optimization of LE, size and potential}

Table 5 Response optimization plot for different responses

\begin{tabular}{|c|c|c|c|c|}
\hline & Value & Alg & CS & $\mathbf{C a C l}_{2}$ \\
\hline LE & $70.3 \%$ & 200 & 200 & 60 \\
\hline Maximum Size & $277 \mathrm{~nm}$ & 200 & 136 & 30 \\
\hline Minimum Size & $43 \mathrm{~nm}$ & 400 & 50 & 60 \\
\hline Zeta potential & $-19 \mathrm{mV}$ & 200 & 129 & 30 \\
\hline
\end{tabular}

In this study, the data was used to build a mathematical model such as linear, linear interaction, linear square and second order model. Table 5 selected mathematical model to optimize the conditions for 70.3\% for LE\% (200 mg Alg, $200 \mathrm{mg}$ CS and 60 $\mathrm{mg} \mathrm{CaCl} 2$ ), minimizing the size (400 mg, $50 \mathrm{mg}$ and $60 \mathrm{mg}$ ). Alg with $200 \mathrm{mg}, \mathrm{CS}$ $129 \mathrm{mg}$ and $30 \mathrm{mg} \mathrm{CaCl} 2$ were determined as optimum zeta potential with $-19 \mathrm{mV}$. 


\subsubsection{Validation test}

The comparison of experimental results with predicted values was shown in Table 6 . From the table, the theoretical values for response were close to experimentally obtained values. This result indicates that the mathematical models can be successfully be used to predict the LE, zeta size and zeta potential values for any combination of the $\mathrm{Alg}, \mathrm{CS}$ and $\mathrm{CaCl}_{2}$ within the range of the performed experimentation.

Table 6Response optimization for LE, zeta size and zeta potential

\begin{tabular}{|c|c|c|c|c|c|c|c|c|c|c|c|c|}
\hline \multirow[t]{2}{*}{ No. } & \multirow[b]{2}{*}{$\frac{0,0}{2}$} & \multirow[b]{2}{*}{ U } & \multirow[b]{2}{*}{$\underbrace{\tilde{U}}_{\tilde{U}}$} & \multicolumn{3}{|c|}{$\% \mathbf{L E}$} & \multicolumn{3}{|c|}{ Zeta Size (nm) } & \multicolumn{3}{|c|}{$\begin{array}{c}\text { Zeta potential } \\
(\mathrm{mV})\end{array}$} \\
\hline & & & & 育 & 迅 & bo & 商 & $\stackrel{8}{E}$ & be & 网 & E्己 & 总 \\
\hline 1 & $\underset{n}{\text { ల }}$ & 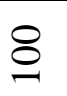 & in & 45.0 & 43.0 & 4.7 & 115 & 126 & 8.7 & -9.5 & -8.9 & 6.7 \\
\hline 2 & 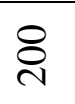 & ঠ্ণ & లి & 43.3 & 45.5 & 4.8 & 285 & 277 & 2.9 & -14.5 & -16.2 & 10.5 \\
\hline 3 & ஜn & $\stackrel{\circ}{2}$ & 운 & 48.8 & 46.0 & 6.1 & 150 & 165 & 9.1 & -10.8 & -11.5 & 6.1 \\
\hline
\end{tabular}

3.8 Release properties of MET from MET-CS-AIgNPs nanocomposites

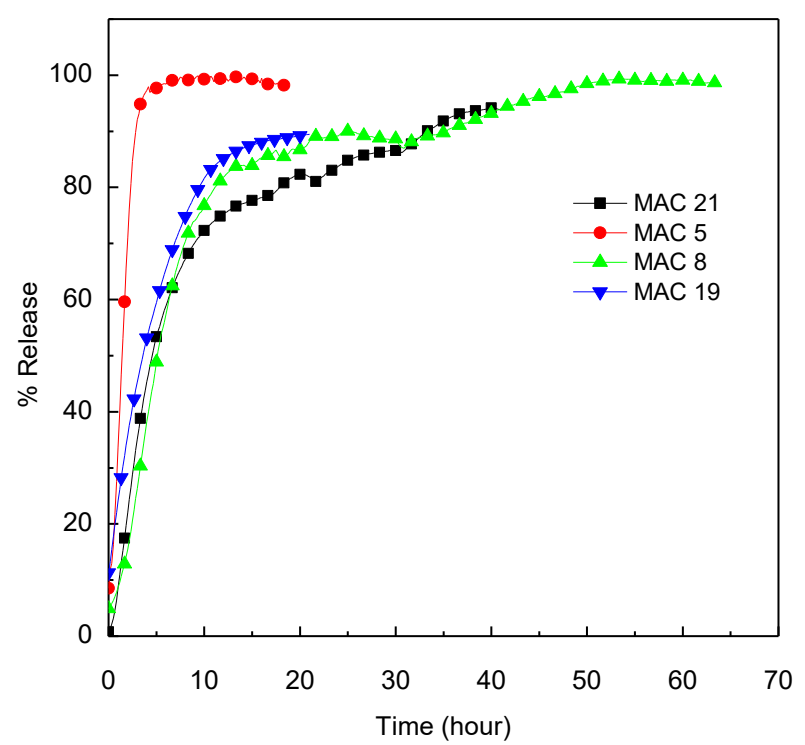

Figure 17 In vitro release behaviours of MET from MET-CS-AlgNPs nanocomposites in the $0.1 \mathrm{~N} \mathrm{HCl}$ 
Figure 17 shows the in vitro MET release profiles from MET-CS-AlgNPs nanocomposites occurred at $\mathrm{pH} 1.2 \mathrm{HCl}$ solutions. It could be found the MET release process from MAC8, MAC21 and MAC19 nanocomposites were separated into two stages. At the first 10 hours, only $77 \%, 72 \%$ and $81 \%$ of MET were released, respectively. The polysaccharides are highly hydrolyzed, so MET can be diffused out quickly and easily [45]. In addition, at the second stage, the release profile of MET presented with slowly sustained release from the nanocomposites.

Table 7 the correlation coefficients $\left(R^{2}\right)$ obtained by fitting the MET release data from MET-CS-AlgNPs nanocomposites HCl solutions at pH 1.2.[46-48]

\begin{tabular}{|c|c|c|c|c|}
\hline \multirow[t]{2}{*}{ Samples } & \multicolumn{4}{|l|}{$\mathbf{R}^{2}$} \\
\hline & $\begin{array}{l}\text { Pseudo-first } \\
\text { order }\end{array}$ & $\begin{array}{l}\text { Pseudo- } \\
\text { second order }\end{array}$ & $\begin{array}{l}\text { Hixson-Crowell } \\
\text { model }\end{array}$ & $\begin{array}{l}\text { Korsmeyer- } \\
\text { Peppas } \\
\text { model }\end{array}$ \\
\hline MAC 8 & 0.917 & 0.988 & 0.781 & 0.877 \\
\hline MAC 21 & 0.943 & 0.856 & 0.734 & 0.882 \\
\hline MAC 19 & 0.930 & 0.990 & 0.822 & 0.891 \\
\hline \multirow[t]{3}{*}{ MAC 5} & 0.664 & 0.977 & 0.787 & 0.856 \\
\hline & $\begin{array}{l}\ln (q e-q t)=\ln \\
q e-k 1 t\end{array}$ & $\begin{array}{l}\mathrm{t} / \mathrm{qt}=1 / \mathrm{k} 2 \mathrm{qe} 2 \\
+\mathrm{t} / \mathrm{qe}\end{array}$ & $\sqrt[3]{M_{o}}-\sqrt[3]{q_{t}}=K t$ & $\frac{\mathrm{q}_{\mathrm{t}}}{\mathrm{q}_{\infty}}=\mathrm{Kt}^{\mathrm{n}}$ \\
\hline & \multicolumn{4}{|c|}{$\begin{array}{l}\mathrm{q}_{\mathrm{e}} \text { is the quantity released at equilibrium released } \\
\mathrm{q}_{\mathrm{t}} \text { is the quantity released at time }(\mathrm{t}) \\
\mathrm{M}_{\mathrm{o}} \text { is the initial quantity of drug in the nanocomposite } \\
\mathrm{q}_{\infty} \text { is the release at infinite time } \\
\mathrm{k} \text { is the rate constant of the release kinetics }\end{array}$} \\
\hline
\end{tabular}

The data of the cumulative release of the MET from the AMAC8, MAC 21, MAC 19, and MAC 5 nanocomposites were fitted and the results indicate that the release of the MET following the second kinetic model for MAC8, MAC19 and MAC 5 nanocomposites. In addition, the MAC21 nanocomposites follow the first kinetic model (Table 7).

\section{Conclusion}

For the multiple linear regression analysis, mathematical models for LE, zeta size and zeta potential were developed using response surface methodology to formulate the input parameters $\mathrm{Alg}, \mathrm{CS}$ and $\mathrm{CaCl}_{2}$ concentrations. Selected mathematical models showed that the developed response surface methodology models were statistically 
significant and suitable for all sanding conditions to have higher $\mathrm{R}^{2}$ and $\mathrm{R}^{2}$-adjusted values. High correlation values were determined between the experimental data and predicted ones. The concentrations of $\mathrm{Alg}, \mathrm{CS}$ and $\mathrm{CaCl}_{2}$ with value $200 \mathrm{mg}, 200 \mathrm{mg}$ and $60 \mathrm{mg}$, respectively were determined as optimum conditions resulting in maximum LE;400 mg, $50 \mathrm{mg}$ and $60 \mathrm{mg}$ respectively, for minimum zeta size and finally $200 \mathrm{mg}, 129 \mathrm{mg}$ and $30 \mathrm{mg}$, respectively for $-19 \mathrm{mV}$ zeta potential. The verification experiment was carried out to check the validity of the developed mathematical model that predicted LE, zeta size and zeta potential within the range of $10 \%$ error limit.

\section{Declaration of conflicting interests}

The authors report no conflicts of interest in this work.

\section{Funding acknowledgement}

The author would like to thank the Faculty of Pharmacy at Isra University, and University Putra Malaysia for provided funding for this research. This study was also supported by Hikma pharmaceuticals Research and development Department.

\section{References}

1. Gandhi, A. and C. Roy, Quality by Design $(Q b D)$ in Pharmaceutical Industry: Tools, Perspectives and Challenges. PharmaTutor, 2016. 4(11): p. 12-20.

2. Singh, B., et al., Formulation development of oral controlled release tablets of hydralazine: optimization of drug release and bioadhesive characteristics. Acta Pharmaceutica, 2009. 59(1): p. 1-13.

3. Singh, B., R. Gupta, and N. Ahuja, Computer-assisted optimization of pharmaceutical formulations and processes. Pharmaceutical Product Development (Ed. NK Jain), CBS Publishers, New Delhi, 2006: p. 273-318.

4. Banker, G.S., J. Siepmann, and C. Rhodes, Modern pharmaceutics. 2002: CRC Press.

5. Armstrong, N.A., Pharmaceutical experimental design and interpretation. 2006: CRC Press.

6. Rao, M., et al., Preparation and evaluation of immediate release tablet of metoclopramide $\mathrm{HCl}$ using simplex centroid mixture design. Int J PharmTech Res, 2010. 2: p. 1105-11.

7. Arora, J.S., Introduction to optimum design. 2004: Elsevier.

8. Lewis, G.A., D. Mathieu, and R. Phan-Tan-Luu, Pharmaceutical experimental design. 1998: CRC press.

9. Rani, A.P. and V. Hema, Full factorial design in formulation of lamotrigine suspension using locust bean gum. International Journal of Chemical Sciences, 2013. 11(2): $p$. 751-760. 
10. KUMAR, R.S., T.N.S. YAGNESH, and V.G. KUMAR, OPTIMISATION OF IBUPROFEN FAST DISSOLVING TABLETS EMPLOYING STARCH XANTHATE USING 23 FACTORIAL DESIGN. Int J App Pharm, 2017. 9(5): p. 51-59.

11. Box, G.E. and J.S. Hunter, The $2 k-p$ fractional factorial designs. Technometrics, 1961. 3(3): p. 311-351.

12. Gunst, R.F. and R.L. Mason, Fractional factorial design. Wiley Interdisciplinary Reviews: Computational Statistics, 2009. 1(2): p. 234-244.

13. Shahabadi, S.M.S. and A. Reyhani, Optimization of operating conditions in ultrafiltration process for produced water treatment via the full factorial design methodology. Separation and Purification Technology, 2014. 132: p. 50-61.

14. Salea, R., et al., Supercritical fluid carbon dioxide extraction of Nigella sativa (black cumin) seeds using taguchi method and full factorial design. Biochemical Compounds, 2013. 1(1): p. 1.

15. Jacques, P., et al. Optimization of biosurfactant lipopeptide production from Bacillus subtilis 5499 by Plackett-Burman design. in Twentieth Symposium on Biotechnology for Fuels and Chemicals. 1999. Springer.

16. Ahuja, S., G. Ferreira, and A. Moreira, Application of Plackett-Burman design and response surface methodology to achieve exponential growth for aggregated shipworm bacterium. Biotechnology and bioengineering, 2004. 85(6): p. 666-675.

17. Sarlak, N., et al., Effects of electrospinning parameters on titanium dioxide nanofibers diameter and morphology: An investigation by Box-Wilson central composite design (CCD). Chemical Engineering Journal, 2012. 210: p. 410-416.

18. Wsól, V.r. and A.F. Fell, Central composite design as a powerful optimisation technique for enantioresolution of the rac-11-dihydrooracin-the principal metabolite of the potential cytostatic drug oracin. Journal of Biochemical and Biophysical methods, 2002. 54(1-3): p. 377-390.

19. Ferreira, S.C., et al., Box-Behnken design: an alternative for the optimization of analytical methods. Analytica chimica acta, 2007. 597(2): p. 179-186.

20. Tak, B.-y., et al., Optimization of color and COD removal from livestock wastewater by electrocoagulation process: application of Box-Behnken design (BBD). Journal of Industrial and Engineering Chemistry, 2015. 28: p. 307-315.

21. Thirugnanasambandham, K., V. Sivakumar, and K. Shine, Optimization of reverse osmosis treatment process to reuse the distillery wastewater using Taguchi design. Desalination and Water Treatment, 2016. 57(51): p. 24222-24230.

22. Luo, W., M. Pla-Roca, and D. Juncker, Taguchi design-based optimization of sandwich immunoassay microarrays for detecting breast cancer biomarkers. Analytical chemistry, 2011. 83(14): p. 5767-5774.

23. O'shea, N., et al., Modelling the effects of orange pomace using response surface design for gluten-free bread baking. Food Chemistry, 2015. 166: p. 223-230.

24. Lesch, S., Sensor-directed response surface sampling designs for characterizing spatial variation in soil properties. Computers and Electronics in Agriculture, 2005. 46(1-3): p. 153-179.

25. Li, T., et al., Quaternized chitosan/alginate nanoparticles for protein delivery. Journal of Biomedical Materials Research Part A: An Official Journal of The Society for Biomaterials, The Japanese Society for Biomaterials, and The Australian Society for Biomaterials and the Korean Society for Biomaterials, 2007. 83(2): p. 383-390.

26. Azhar, F.F. and A. Olad, A study on sustained release formulations for oral delivery of 5-fluorouracil based on alginate-chitosan/montmorillonite nanocomposite systems. Applied Clay Science, 2014. 101: p. 288-296.

27. Dai, Y.N., et al., Swelling characteristics and drug delivery properties of nifedipine-loaded $\mathrm{pH}$ sensitive alginate-chitosan hydrogel beads. Journal of 
Biomedical Materials Research Part B: Applied Biomaterials: An Official Journal of The Society for Biomaterials, The Japanese Society for Biomaterials, and The Australian Society for Biomaterials and the Korean Society for Biomaterials, 2008. 86(2): p. 493-500.

28. Taleb, M.F.A., A. Alkahtani, and S.K. Mohamed, Radiation synthesis and characterization of sodium alginate/chitosan/hydroxyapatite nanocomposite hydrogels: a drug delivery system for liver cancer. Polymer Bulletin, 2015. 72(4): p. 725-742.

29. Dubnika, A., D. Loca, and L. Berzina-Cimdina, Functionalized hydroxyapatite scaffolds coated with sodium alginate and chitosan for controlled drug delivery. Proceedings of the Estonian Academy of Sciences, 2012. 61(3): p. 193.

30. Freiberg, S. and X.X. Zhu, Polymer microspheres for controlled drug release. International Journal of Pharmaceutics, 2004. 282(1): p. 1-18.

31. Mayol, L., et al., Design of electrospayed non-spherical poly (I-lactide-co-glicolide) microdevices for sustained drug delivery. Journal of Materials Science: Materials in Medicine, 2014. 25(2): p. 383-390.

32. Deshmukh, R.K. and J.B. Naik, Aceclofenac microspheres: Quality by design approach. Materials Science and Engineering: C, 2014. 36: p. 320-328.

33. Jiang, F., et al., Strontium-substituted, luminescent and mesoporous hydroxyapatite microspheres for sustained drug release. Journal of Materials Science: Materials in Medicine, 2014. 25(2): p. 391-400.

34. Rajaonarivony, M., et al., Development of a new drug carrier made from alginate. Journal of pharmaceutical sciences, 1993. 82(9): p. 912-917.

35. Montgomery, D.C., Design and analysis of experiments. ed. John Wiley \& Sons, 2001. 52: p. 218-286.

36. Trivedi, M.K., et al., Characterization of physicochemical and thermal properties of chitosan and sodium alginate after biofield treatment. 2015.

37. Kumari, S.D.C., et al., Formulation and characterization of Methotrexate loaded sodium alginate chitosan Nanoparticles. Indian Journal of Research in Pharmacy and Biotechnology, 2013. 1(6): p. 915.

38. de Souza, N., et al., Thermal stability of metronidazole drug and tablets. Journal of thermal analysis and calorimetry, 2003. 72(2): p. 535-538.

39. Anand, M., et al., Synthesis of chitosan nanoparticles by TPP and their potential mosquito larvicidal application. Frontiers in Laboratory Medicine, 2018. 2(2): p. 7278.

40. Kulig, D., et al., Study on alginate-chitosan complex formed with different polymers ratio. Polymers, 2016. 8(5): p. 167.

41. Neto, C.d.T., et al., Thermal analysis of chitosan based networks. Carbohydrate Polymers, 2005. 62(2): p. 97-103.

42. Mukhopadhyay, P. and P. Paban Kundu, Chitosan-graft-PAMAM / alginate core-shell nanoparticles: A safe and promising oral insulin carrier in Animal Model. RSC Adv., 2015. 5.

43. Ghadiri, M., et al., Loading hydrophilic drug in solid lipid media as nanoparticles: Statistical modeling of entrapment efficiency and particle size. International journal of pharmaceutics, 2012. 424(1-2): p. 128-137.

44. Javaid, M.A., et al., Mathematical modeling and experimental study of mechanical properties of chitosan based polyurethanes: Effect of diisocyanate nature by mixture design approach. International Journal of Biological Macromolecules, 2019. 124: p. 321-330. 
45. Wang, F., et al., Effective method of chitosan-coated alginate nanoparticles for target drug delivery applications. Journal of biomaterials applications, 2016. 31(1): p. 3-12.

46. Dong, L., et al., Synthesis and release behavior of composites of camptothecin and layered double hydroxide. J Solid State Chem, 2010. 183(8): p. 1811-1816.

47. Ho, Y.-S. and A.E. Ofomaja, Pseudo-second-order model for lead ion sorption from aqueous solutions onto palm kernel fiber. J Hazard Mater 2006. 129(1): p. 137-142.

48. Sakore, S. and B. Chakraborty, Formulation and evaluation of enalapril maleate sustained release matrix tablets. Int J Pharm, 2013. 4(1): p. 21-26. 